Part of Journal of Research of the National Bureau of Standards, Volume 21, September 1938

\title{
STRENGTH OF A RIVETED STEEL RIGID FRAME HAVING STRAIGHT FLANGES
}

\author{
By Ambrose H. Stang, Martin Greenspan, and William R. Osgood
}

\section{ABSTRACT}

The distribution of stress in and near the knee of a riveted steel rigid-frame specimen having straight flanges was investigated both experimentally and theoretically for various conditions of loading. The theory developed for the distribution of stress in the knee gave stresses which agreed within the experimental error with those obtained experimentally. Reinforcing the outer corner was shown to have little effect on the stress distribution in the frame. The maximum load that could be sustained by the specimen was determined.

\section{CONTENTS}

Page

II. Rigid-frame specimen

1. Description of the specimen

2. Tensile properties of the material

III. Testing procedure

IV. Measured stresses

Y. Theory for web of knee.

VI. Theoretical stresses _.

VII. Greatest stresses.

1. The legs

2. The knee web

(a) Greatest normal stress

(b) Greatest shearing stress_

VIII. Maximum load _.

IX. Conclusions.

X. Appendix - Stresses from strain data

XI. References_...

\section{INTRODUCTION}

A rigid frame is a portion of a structure in which ends of component members are connected in such a way as to prevent relative rotation of the ends at the connection. Steel rigid frames are usually built up from plates and angles, like a plate girder.

Rigid frames are being increasingly used in the construction of bridges, warehouses, auditoriums, etc. [1] ${ }^{1}$ The fundamental reason for the increasing use of rigid frames is their economy. General sturdiness and ease of maintenance are other advantages. An example of recent rigid-frame construction is shown in figure 1.

A rigid frame is analyzed much like an arch, either two-hinged or fixed, depending upon the conditions at the foundations [2, 3]. How-

\footnotetext{
1 Figures in brackets indicate the references at the end of this paper.
} 
ever, ordinary methods of design do not apply to a knee, or junction of two members, because of the abrupt change in direction of the members at this point. The stresses in rigid frames have been estimated by photoelastic methods $[4,5,6]$. The strains in reinforcedconcrete frames have been determined by the use of strain gages [6]. However, no numerical values for the stresses in a steel rigid frame were found in the literature.

The American Institute of Steel Construction, through its chief engineer, F. H. Frankland, approached the National Bureau of Standards with a program of research on the stress distribution in steel rigid frames. The work was authorized in April and begun in July 1935 . The Institute arranged to secure three frames and cooperated by maintaining a research associate at the Bureau and by publishing 10 progress reports during the course of the investigation.

This paper gives the results of the tests on a steel rigid-frame specimen donated by the Bethlehem Steel Co. Tests on other steel frames will be reported in later papers. The distribution of stress in the specimen was determined both experimentally and theoretically. The experimental work consisted in loading the specimen and measuring the strains on a sufficiently large number of gage lines to determine the state of strain, from which the state of stress could be determined by standard methods. The theoretical work was undertaken at the suggestion of H. D. Hussey of the American Bridge Co., who cooperated effectively and made an extensive independent study of this important problem. Many valuable suggestions were received from F. H. Frankland, chief engineer of the Institute, and from the Institute's Committee on Technical Research, consisting of Jonathan Jones, chairman, H. G. Balcom, O. E. Hovey, H. D. Hussey, J. R. Lambert, Aubrey Weymouth, and F. H. Frankland (ex officio).

\section{RIGID-FRAME SPECIMEN}

\section{DESCRIPTION OF THE SPECIMEN}

The rigid-frame specimen is shown in figure 2. It was fabricated from steel plates and angles joined by riveting. The weight as determined by the Bethlehem Steel Co. was 3,610 lb. The lower leg and the knee were fabricated as a unit. The upper leg was spliced to the knee at the inner flange angles of the lower leg. It was intended that the inner flange angles of the upper leg abut on those of the lower leg at the inner corner of the knee, but actually there was some lack of bearing (leaving a maximum clearance of $1 / 32$ in.). There was also some lack of bearing at the inner corner of the knee between the ends of the lower-leg stiffener angles and the outstanding legs of the inner flange angles of the lower leg. The outer corner of the knee was built so that it could be reinforced by a gusset on each side secured by turned bolts in reamed holes.

The rigid-frame specimen is shown in the testing machine in figure 3.

\section{TENSILE PROPERTIES OF THE MATERIAL}

Samples were taken from the flange angles and web plates before fabrication, and marked $A R, A L, C$, etc., for identification, as shown in figure 2. The tensile properties of the material were determined from coupons machined from these samples. The coupons were ASTM 8-in.-gage-length tensile specimens for plates, shapes, and 


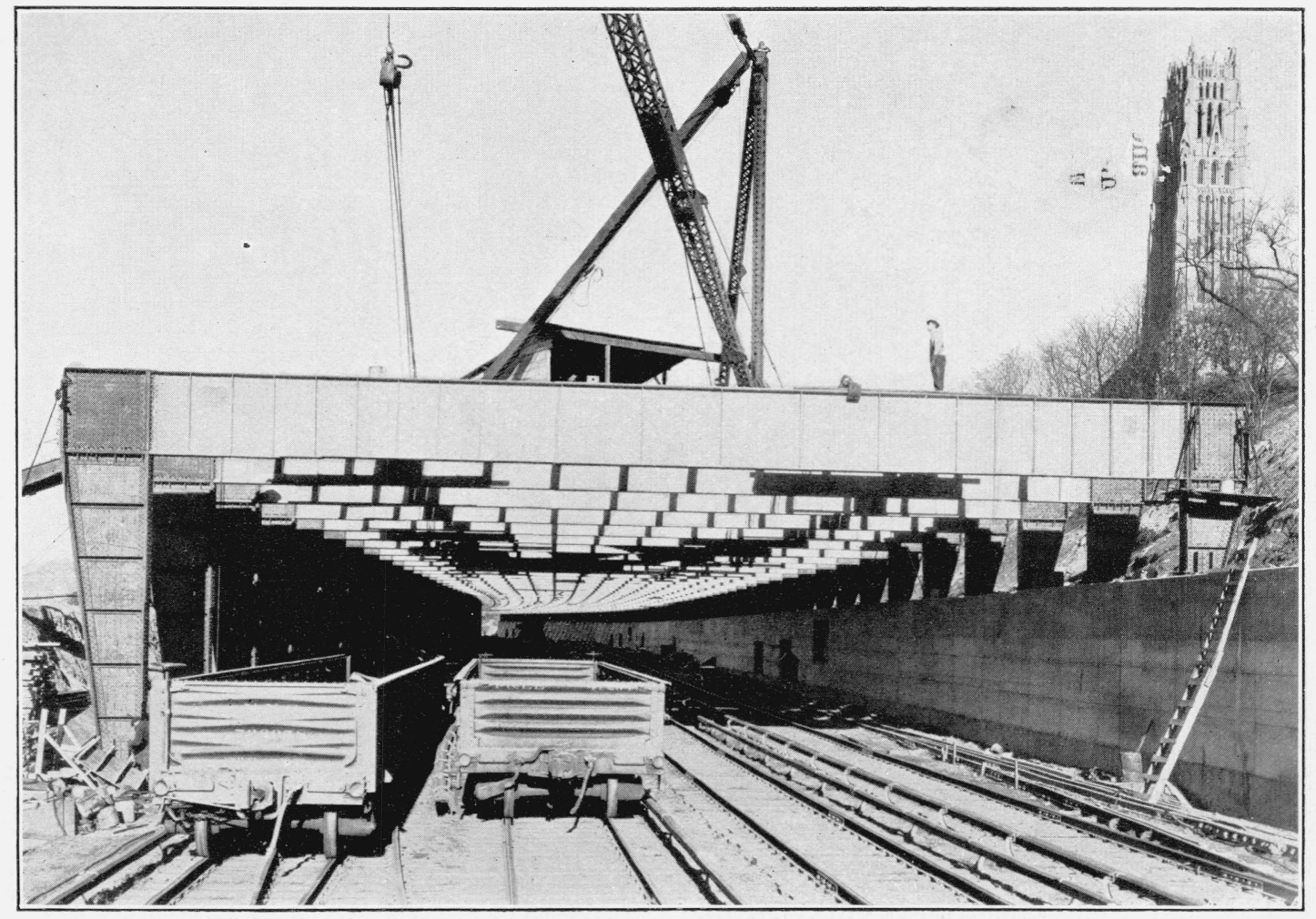

Figure 1.- Steel rigid frames, West Side Improvement, New York City.

Approximately 12,000 tons of structural steel, comprising 397 frames, were involved in this development. 


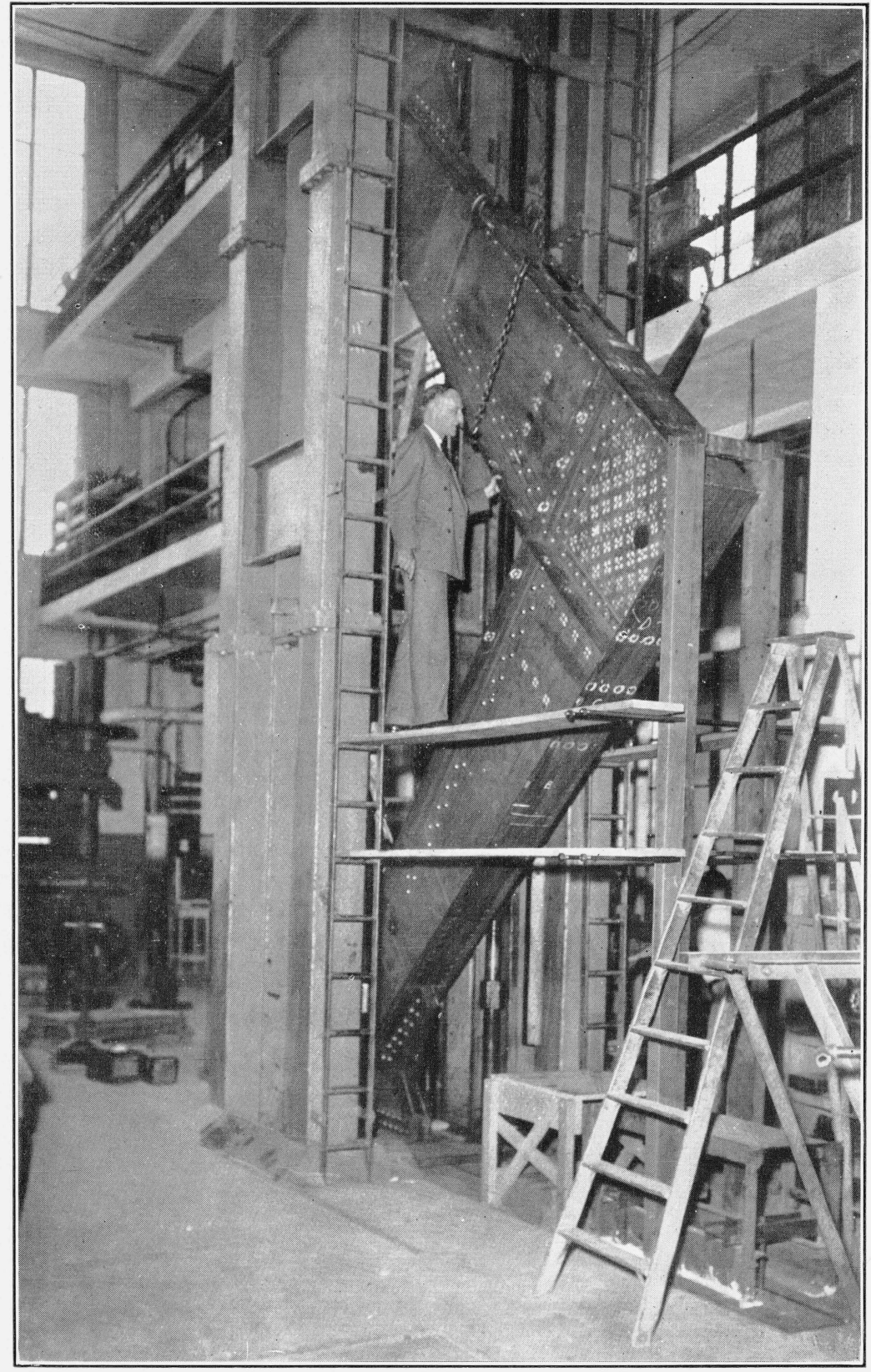

FIGURE 3.-Rigid-frame specimen in the testing machine. 
flats [7]. The width of the coupons at the reduced section was 1.5 in., and the thickness was that of the material as rolled.

The coupons were tested in a screw-driven, beam-and-poise testing machine having a capacity of $100 \mathrm{kips}^{2}$. The speed of the movable platen of the testing machine was $0.008 \mathrm{in}$./min until the extensometer was removed from the coupon. Thereafter the speed of the movable platen was $0.4 \mathrm{in} . / \mathrm{min}$.

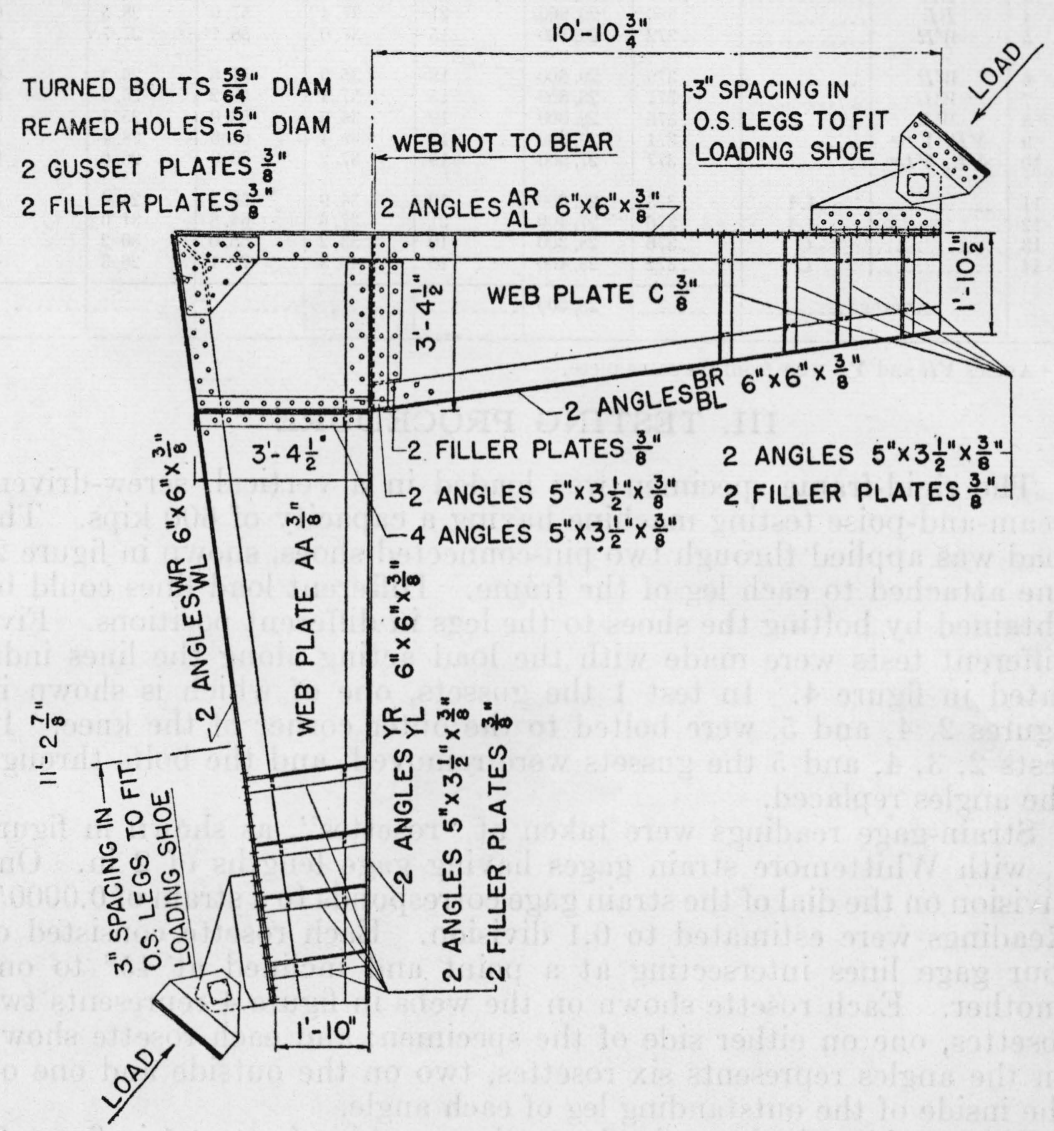

FIGURE 2.-Dimensions of the rigid-frame specimen and location of the coupons.

The strains were determined by means of a Ewing extensometer of 8 -in. gage length. One division on the scale of this instrument corresponds to a strain of 0.000025 . Readings were estimated to 0.1 division.

The yield point was determined by the drop-of-beam method. Young's modulus of elasticity and the proportional limit were determined from difference curves [8].

The tensile properties of the material are given in table 1.

\footnotetext{
$21 \mathrm{kip}=1,000 \mathrm{lb}$.
} 
TABLE 1.-Tensile properties of the material

\begin{tabular}{|c|c|c|c|c|c|c|c|c|c|}
\hline \multirow{2}{*}{$\begin{array}{l}\text { Cou- } \\
\text { pon } \\
\text { No. }\end{array}$} & \multicolumn{2}{|c|}{ Coupon from- } & \multirow{2}{*}{$\begin{array}{l}\text { Thick- } \\
\text { ness }\end{array}$} & \multirow{2}{*}{$\begin{array}{l}\text { Young's } \\
\text { modulus } \\
\text { of elas- } \\
\text { ticity }\end{array}$} & \multirow{2}{*}{$\begin{array}{l}\text { Propor- } \\
\text { tional } \\
\text { limit }\end{array}$} & \multirow{2}{*}{$\begin{array}{l}\text { Yield } \\
\text { point }\end{array}$} & \multirow{2}{*}{$\begin{array}{l}\text { Tensile } \\
\text { strength }\end{array}$} & \multirow{2}{*}{$\begin{array}{l}\text { Elonga- } \\
\text { tion in } \\
8 \text { in. }\end{array}$} & \multirow{2}{*}{$\begin{array}{l}\text { Reduc- } \\
\text { tion of } \\
\text { area }\end{array}$} \\
\hline & Angle & Plate & & & & & & & \\
\hline $\begin{array}{l}1 \\
2 \\
3 \\
4 \\
5\end{array}$ & $\begin{array}{l}A R \\
A L \\
B R \\
B L \\
W R\end{array}$ & & $\begin{array}{l}\text { in. } \\
0.380 \\
.384 \\
.387 \\
.386 \\
.372\end{array}$ & $\begin{array}{r}\text { kips/in.2 } \\
28,300 \\
29,100 \\
28,000 \\
29,900 \\
28,500\end{array}$ & $\begin{array}{r}\text { kips/in. }{ }^{2} \\
23 \\
22 \\
26 \\
21 \\
15\end{array}$ & $\begin{array}{r}\text { kips/in. }{ }^{2} \\
38.3 \\
36.7 \\
38.9 \\
37.4 \\
37.0\end{array}$ & $\begin{array}{r}\text { kips/in. }{ }^{2} \\
60.8 \\
56.6 \\
62.6 \\
57.0 \\
58.1\end{array}$ & $\begin{array}{l}\% \\
29.0 \\
28.7 \\
27.9 \\
28.5 \\
27.7\end{array}$ & $\begin{array}{ll}\% \quad 60 \\
\quad 60 \\
56 \\
61 \\
55\end{array}$ \\
\hline $\begin{array}{r}6 \\
7 \\
8 \\
9 \\
10\end{array}$ & $\begin{array}{c}W R \\
W L \\
W L \\
Y R, Y L^{a} \\
Y R, Y L^{a}\end{array}$ & & $\begin{array}{l}.379 \\
.371 \\
.376 \\
.371 \\
.377\end{array}$ & $\begin{array}{l}29,600 \\
28,300 \\
28,000 \\
29,200 \\
27,900\end{array}$ & $\begin{array}{l}18 \\
15 \\
19 \\
15 \\
19\end{array}$ & $\begin{array}{l}35.9 \\
37.4 \\
36.6 \\
38.4 \\
37.2\end{array}$ & $\begin{array}{l}57.6 \\
58.2 \\
58.0 \\
61.6 \\
60.9\end{array}$ & $\begin{array}{l}26.2 \\
26.0 \\
25.3 \\
28.4 \\
26.6\end{array}$ & $\begin{array}{l}6 \\
5 ? \\
5 ? \\
57 \\
60\end{array}$ \\
\hline \multirow[t]{2}{*}{$\begin{array}{l}11 \\
12 \\
13 \\
14\end{array}$} & - & \multirow[t]{2}{*}{$\begin{array}{c}A A \\
A A \\
C \\
C\end{array}$} & $\begin{array}{l}.373 \\
.376 \\
.376 \\
.372\end{array}$ & $\begin{array}{l}29,000 \\
27,400 \\
28,300 \\
28,400\end{array}$ & $\begin{array}{l}10 \\
21 \\
10 \\
16\end{array}$ & $\begin{array}{l}34.9 \\
37.6 \\
33.2 \\
40.3 \\
\end{array}$ & $\begin{array}{l}58.5 \\
64.8 \\
55.0 \\
70.1 \\
\end{array}$ & $\begin{array}{l}24.0 \\
31.0 \\
30.2 \\
26.3\end{array}$ & $\begin{array}{l}59 \\
55 \\
63 \\
49\end{array}$ \\
\hline & (2) & & 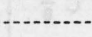 & 28,600 & & & & & \\
\hline
\end{tabular}

a Angles $Y R$ and $Y L$ were from the same piece.

\section{TESTING PROCEDURE}

The rigid-frame specimen was loaded in a vertical, screw-driven, beam-and-poise testing machine having a capacity of 600 kips. The load was applied through two pin-connected shoes, shown in figure 2, one attached to each leg of the frame. Different load lines could be obtained by bolting the shoes to the legs in different positions. Five different tests were made with the load acting along the lines indicated in figure 4 . In test 1 the gussets, one of which is shown in figures 2,4 , and 5 , were bolted to the outer corner of the knee. In tests $2,3,4$, and 5 the gussets were removed, and the bolts through the angles replaced.

Strain-gage readings were taken at "rosettes", as shown in figure 4 , with Whittemore strain gages having gage lengths of 2 in. One division on the dial of the strain gage corresponds to a strain of 0.00005 . Readings were estimated to 0.1 division. Each rosette consisted of four gage lines intersecting at a point and inclined at $45^{\circ}$ to one another. Each rosette shown on the webs in figure 4 represents two rosettes, one on either side of the specimen; and each rosette shown on the angles represents six rosettes, two on the outside and one on the inside of the outstanding leg of each angle.

The specimen is shown in the testing machine for test 1 in figure 3. Strain-gage readings were taken at compressive loads of 5 kips and 80 kips. In test 1 all the strain-gage readings at the load of 5 kips were taken before the specimen was subjected to a higher compressive load. The results of test 1 indicated, however, that preloading of the specimen was desirable, and in the subsequent tests a compressive load of 82 kips was applied and released five times before strain-gage readings were taken.

\section{MEASURED STRESSES}

Stresses computed from the strain-gage readings will be called measured stresses. These stresses were computed from the strains due to the 75-kip increase in load by the methods outlined in the 


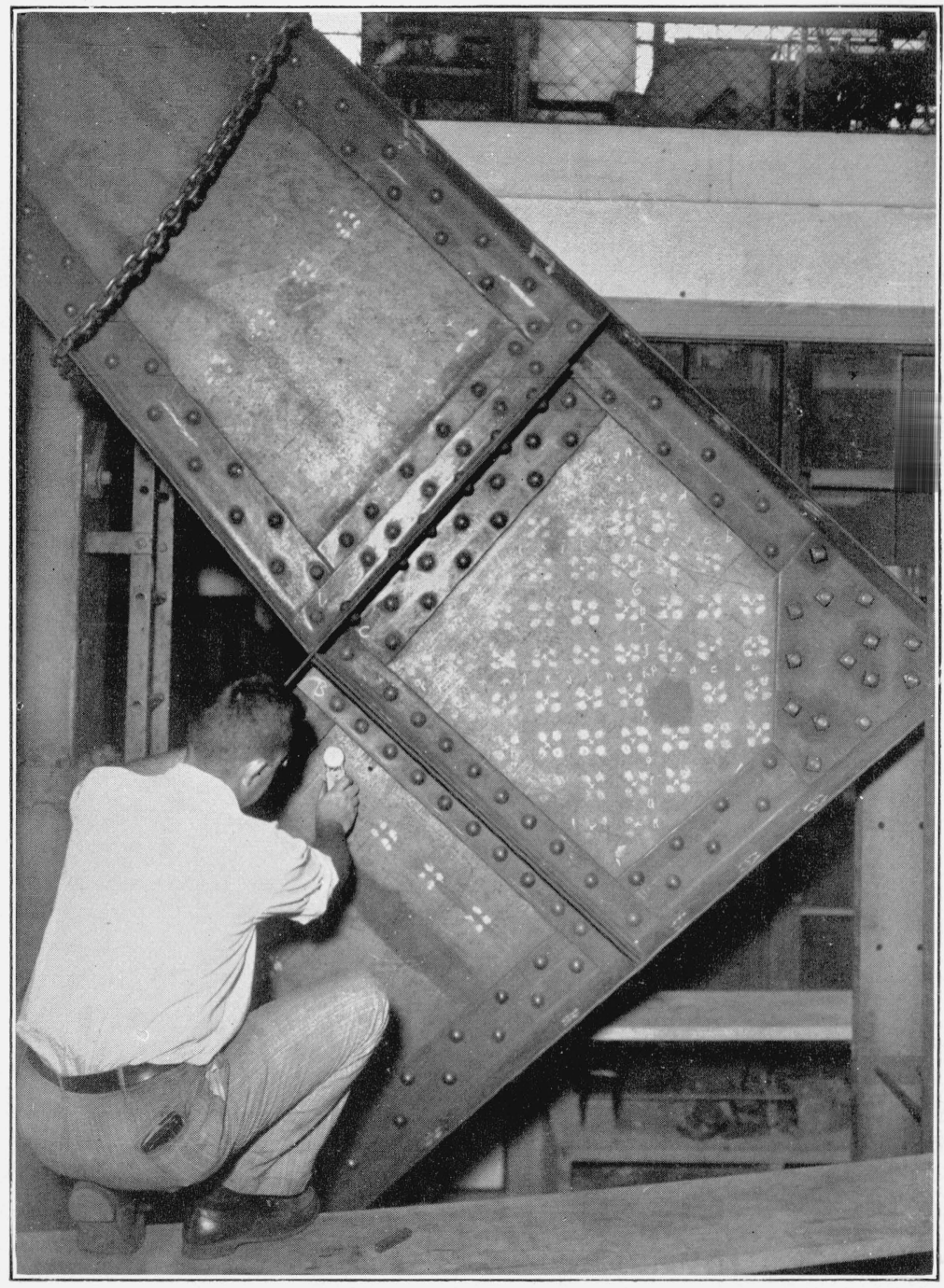

FIGURE 5.-Test 1. Knee of the rigid-frame specimen. 
Appendix (case 1). ${ }^{3}$ The strains in corresponding gage lines on opposite sides of the webs of the specimen were averaged and the average values used in the computations. In the case of the outstanding legs of the flange angles the strains in corresponding gage lines of the six rosettes were averaged and the average values used in the computations. The magnitudes and directions of the principal stresses and of the maximum shearing stress at each rosette were computed.

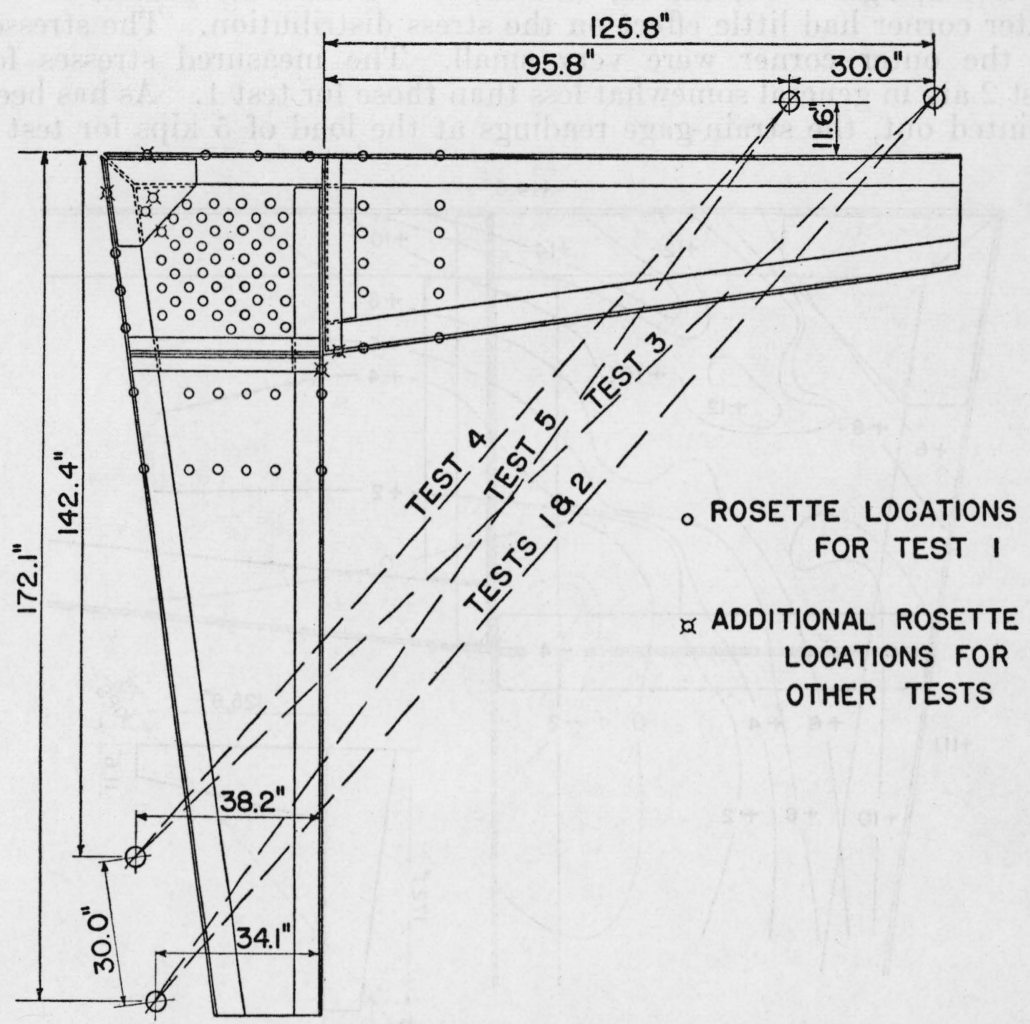

FIGURE 4.-Load lines and location of the rosettes for strain-gage readings.

The results of these computations are shown for test 1 in figures 6 to 9 , inclusive. Figure 6 is a contour chart of maximum principal stress. Each contour line is a locus of points of equal maximum principal stress in the plane of stress. The contour lines show only the magnitudes of the stress. The directions of the contour lines are not the directions of the maximum principal stresses. The contour lines do not give the values of the stresses in the stiffeners. Similar contour charts of minimum principal stress and of maximum shearing stress are shown in figures 7 and 8 , respectively, except that the contour lines of maximum shearing stress in figure 8 were drawn for the three-dimensional state of stress. At any point at which the

3 The greatest deviation of any value of the modulus of elasticity from the average value was about 4.5 percent (table 1). The average value was used for computing the stresses, because it was estimated that the error in the strain-gage readings was greater than 4.5 percent. 
principal stresses in the plane of stress are of the same sign, the maximum shearing stress occurs in planes at $45^{\circ}$ to the plane of stress and is equal to one-half the numerically larger of these principal stresses. The magnitudes and directions of the principal stresses in the plane of stress are shown in figure 9 .

The results of tests $2,3,4$, and 5, are shown in the same way in figures 10 to 25 , inclusive.

Comparison of the results of test 1 , figures $6,7,8$, and 9 , with those of test 2 , figures $10,11,12$, and 13 , shows that the gussets at the outer corner had little effect on the stress distribution. The stresses at the outer corner were very small. The measured stresses for test 2 are in general somewhat less than those for test 1 . As has been pointed out, the strain-gage readings at the load of 5 kips for test 1

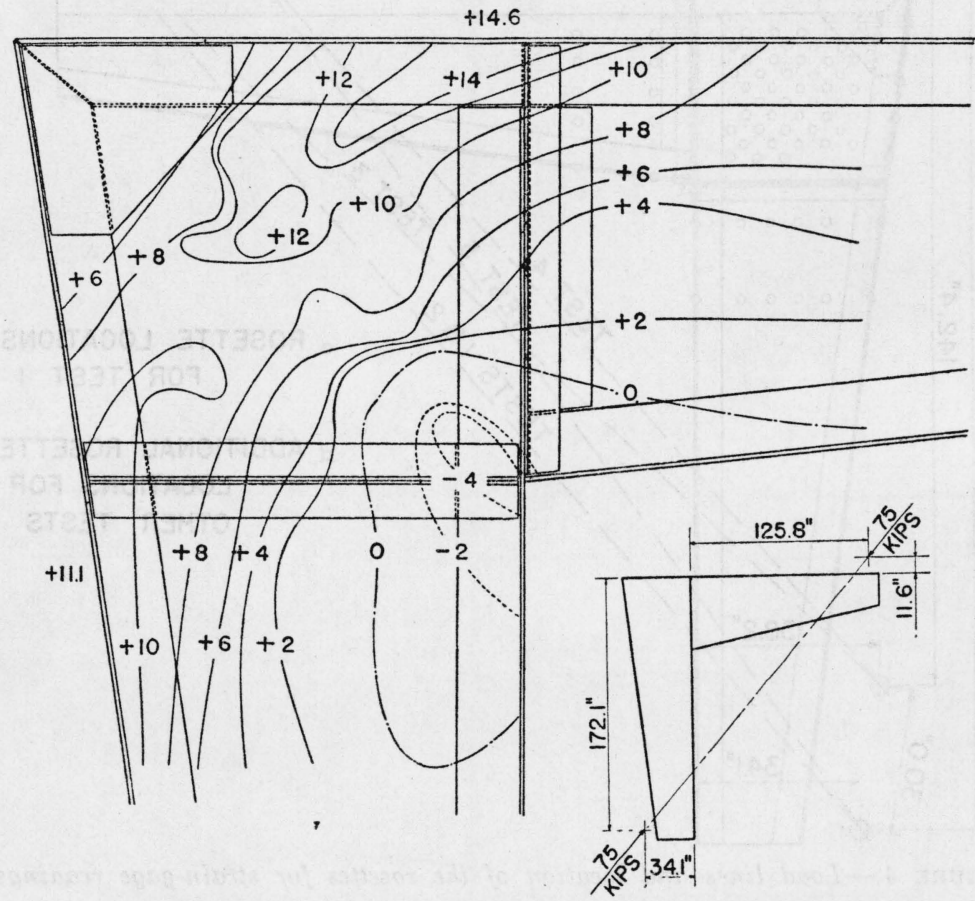

Figure 6.-Test 1. Maximum principal stress, kips/in².

were taken before the frame was subjected to a higher load. From the tensile properties of the material, given in table 1 , it is seen that the proportional limit was exceeded in some places in test 1 . It is probable that the loading of test 1 and the repeated loadings before test 2 brought the material in the frame to a more nearly elastic condition for test 2 than for test 1 , and that the initial, low proportional limits were increased by the cold work of the material. The strains would then be less for a given load and the measured stresses smaller than those for the initial inelastic condition.

The influence of the position of the load line on the stress distribution is evident from a comparison of the results for tests $2,3,4$, and 5 . All other conditions were the same for these tests. 


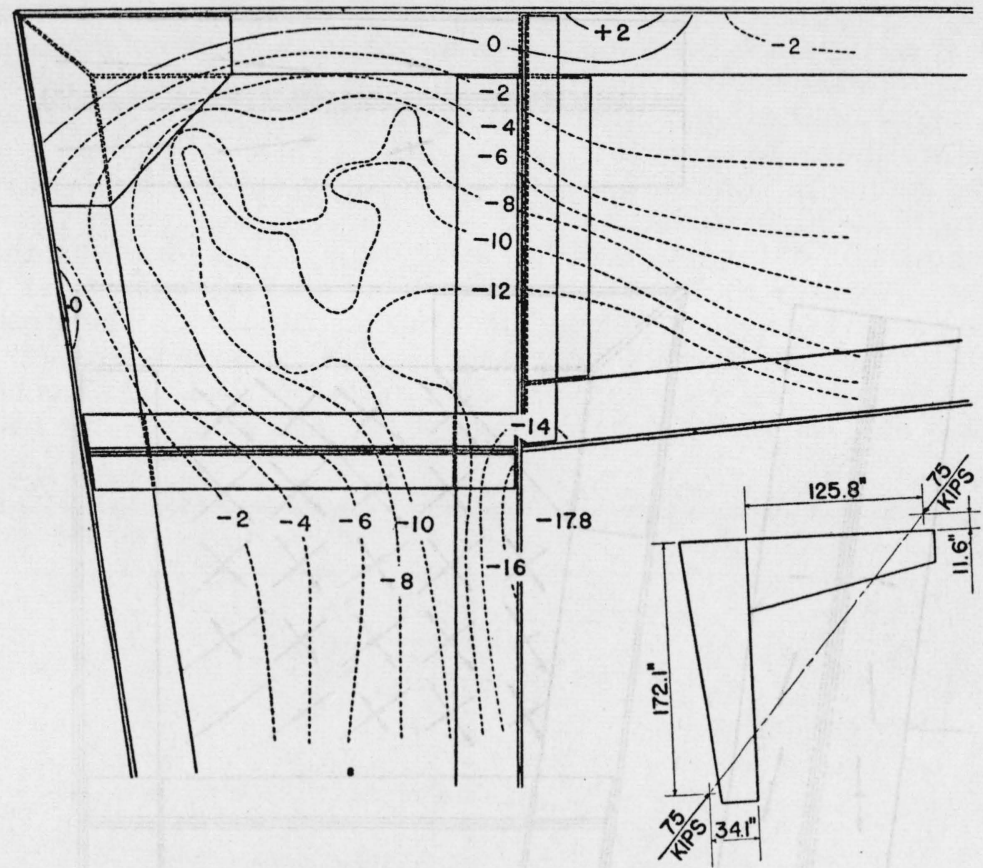

Figure 7.-Test 1. Minimum principal stress, kips/in ${ }^{2}$.

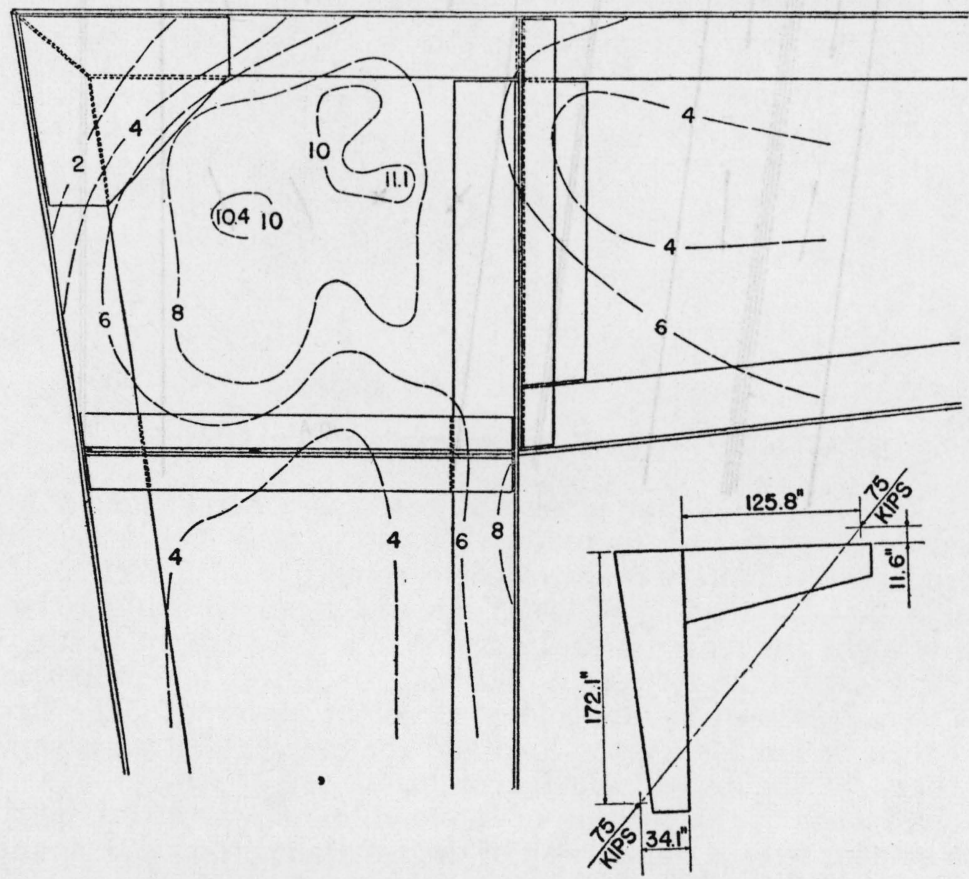

Figure 8.-Test 1. Maximum shearing stress, kips/in ${ }^{2}$. 


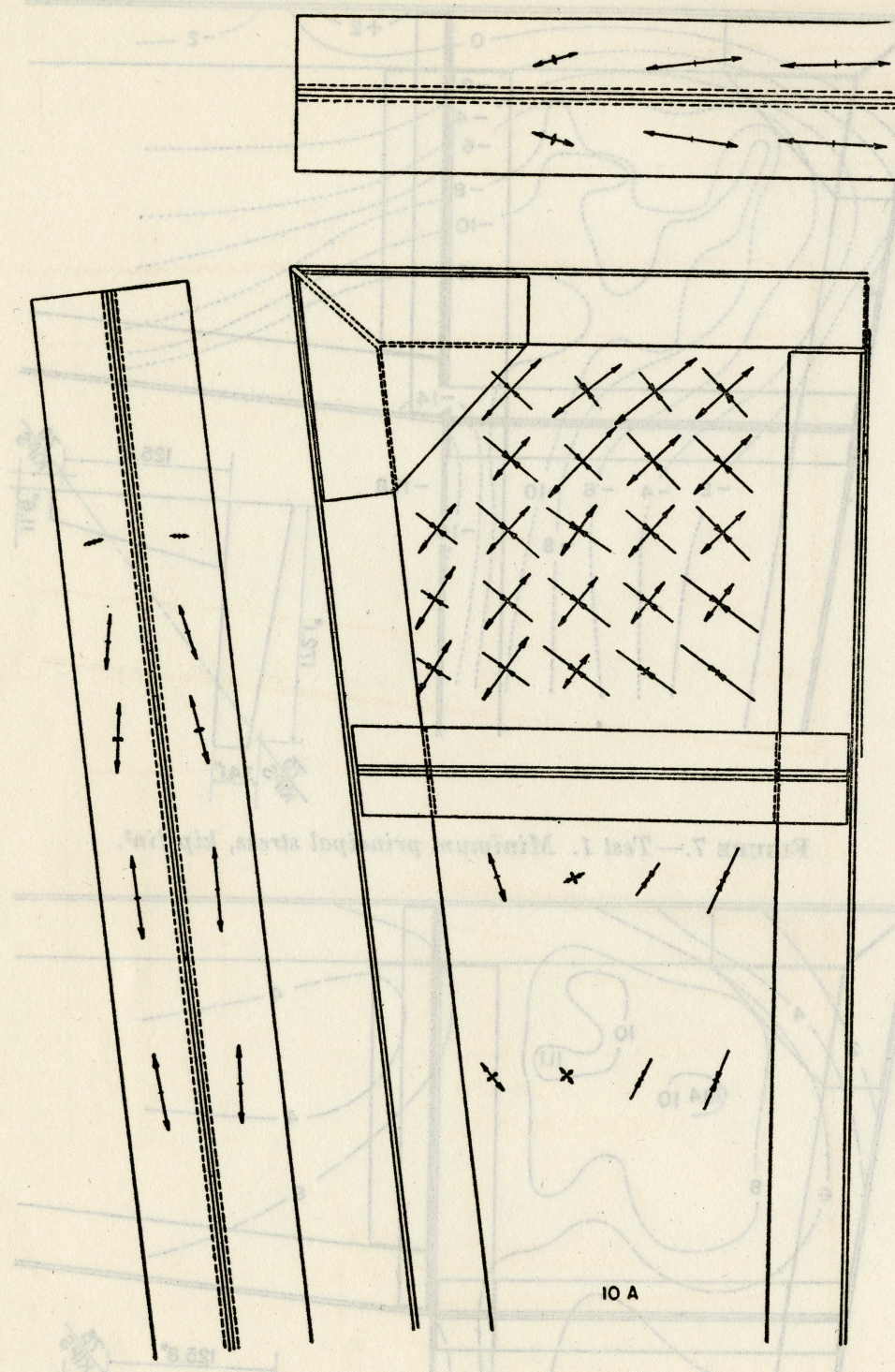



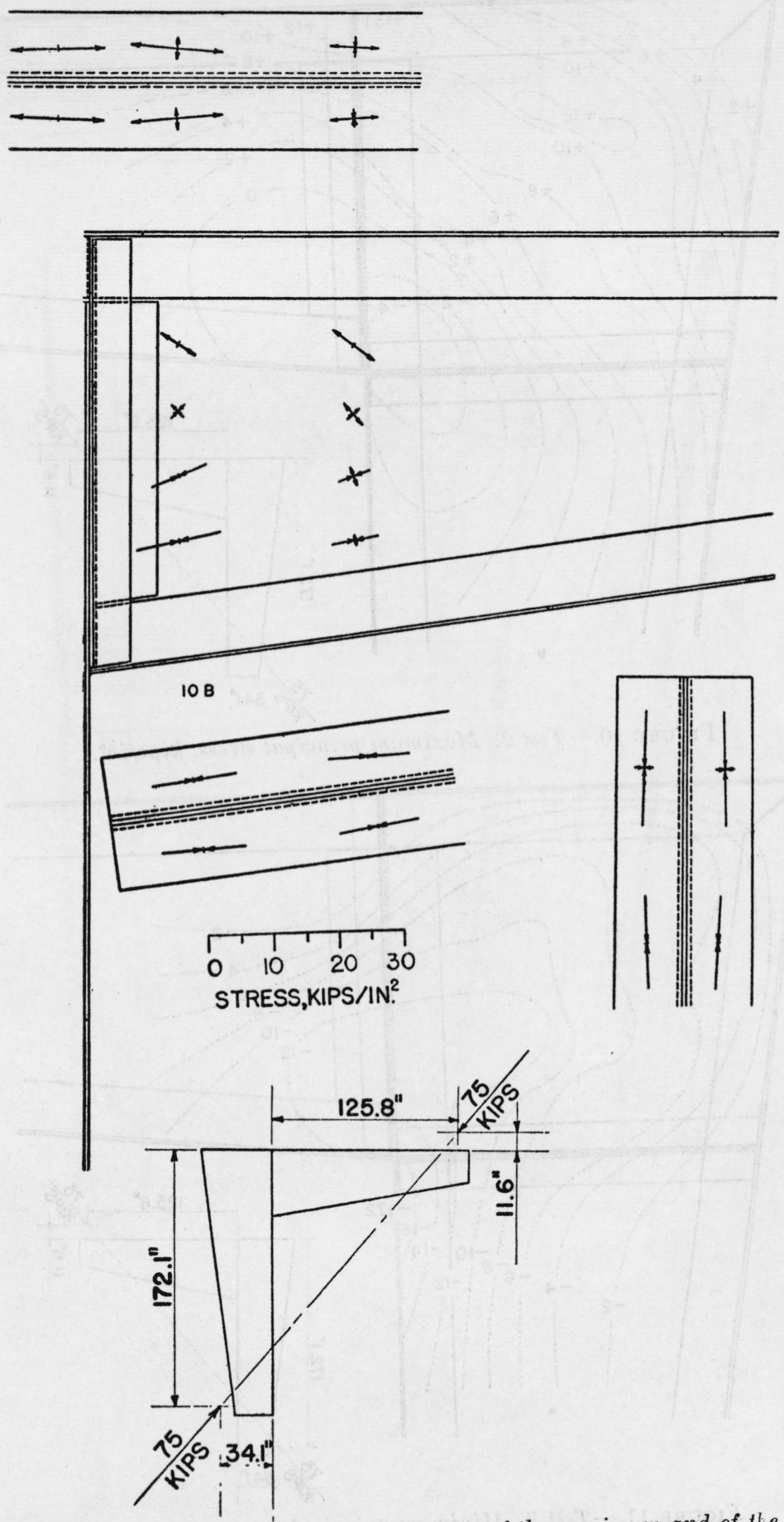

T-Test 1. Magnitude and direction of the maximum and of the minimum principal stresses, kips/in ${ }^{2}$. 


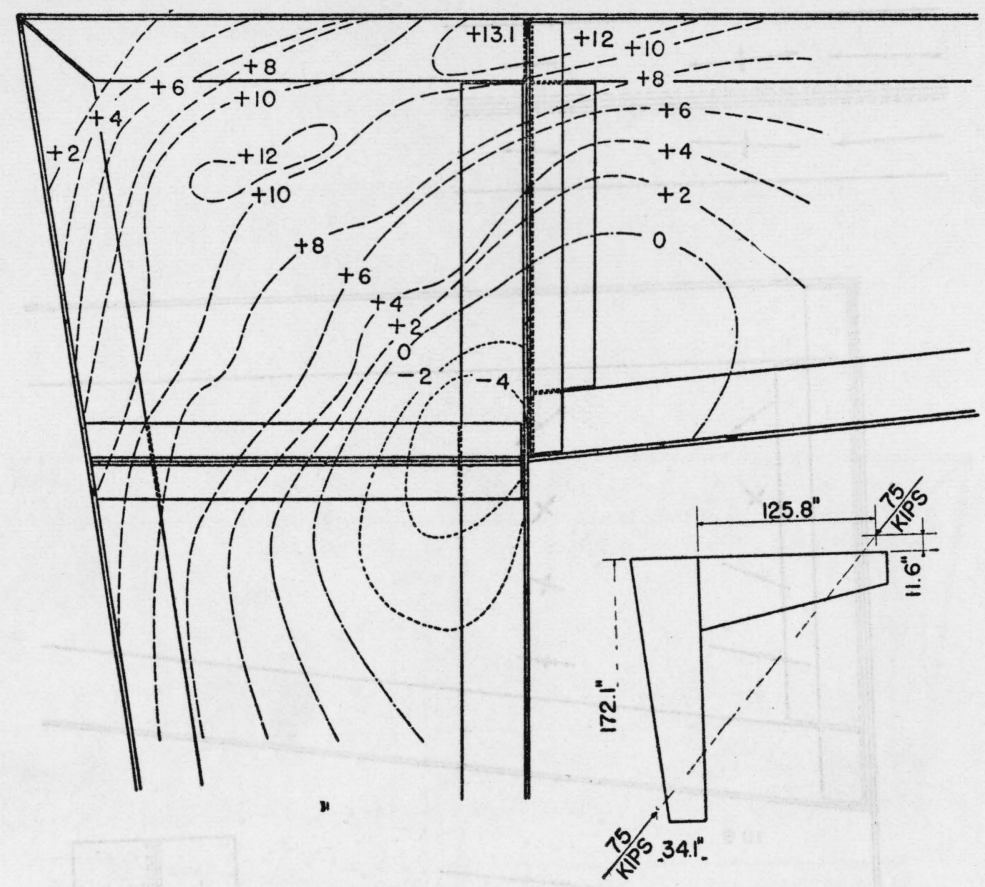

Figure 10.-Test 2. Maximum principal stress, kips/in².

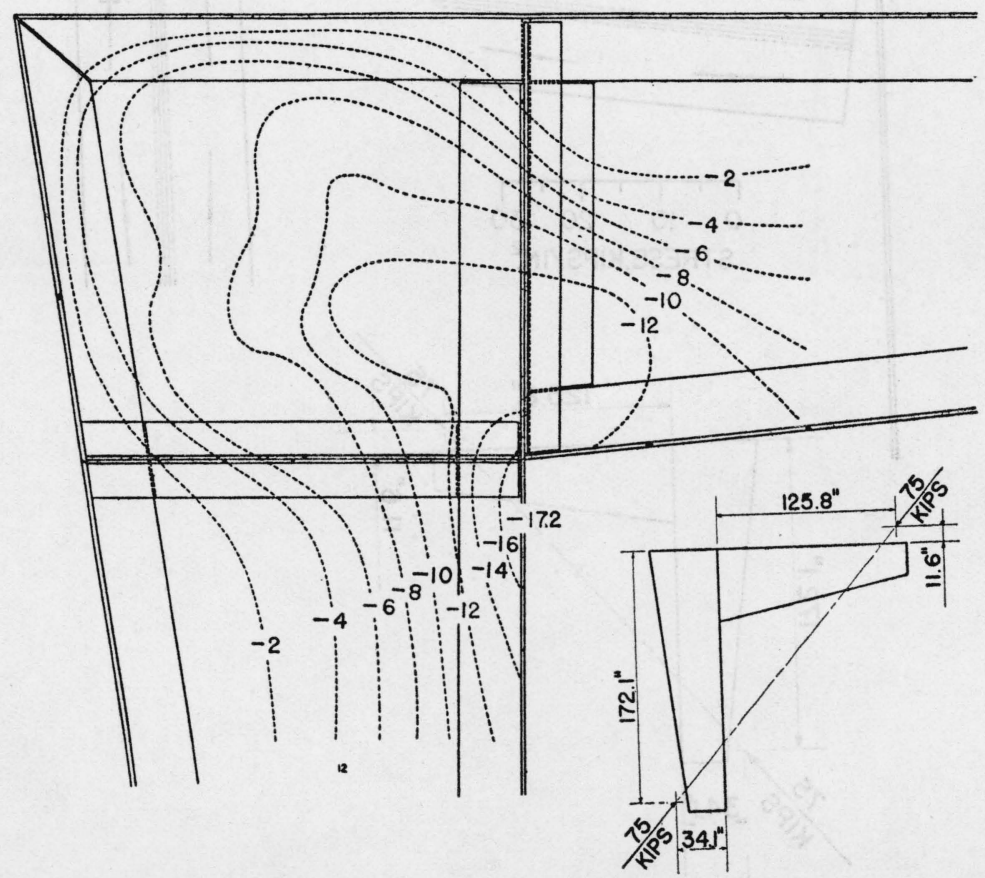

FigdRe 11.-Test 2. Minimum principal stress, kips/in². 


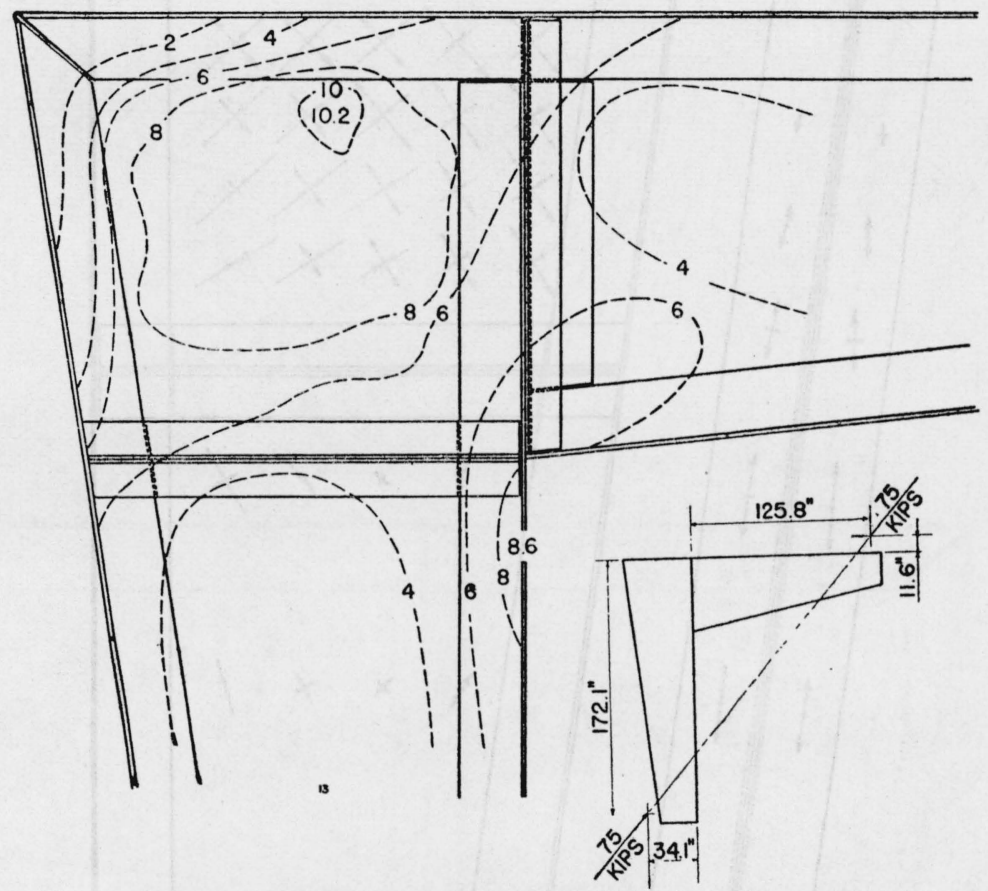

Figure 12.-Test 2. Maximum shearing stress, kips/in². 


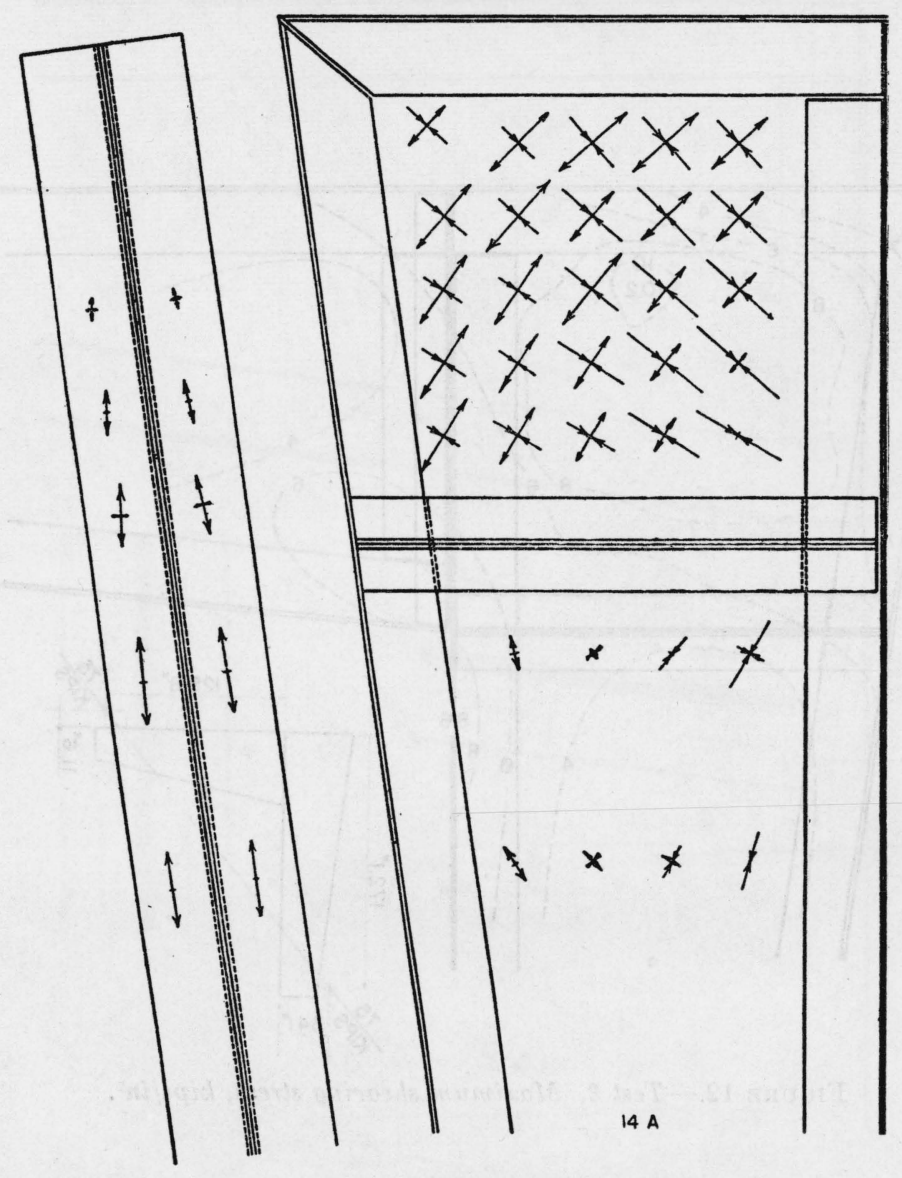



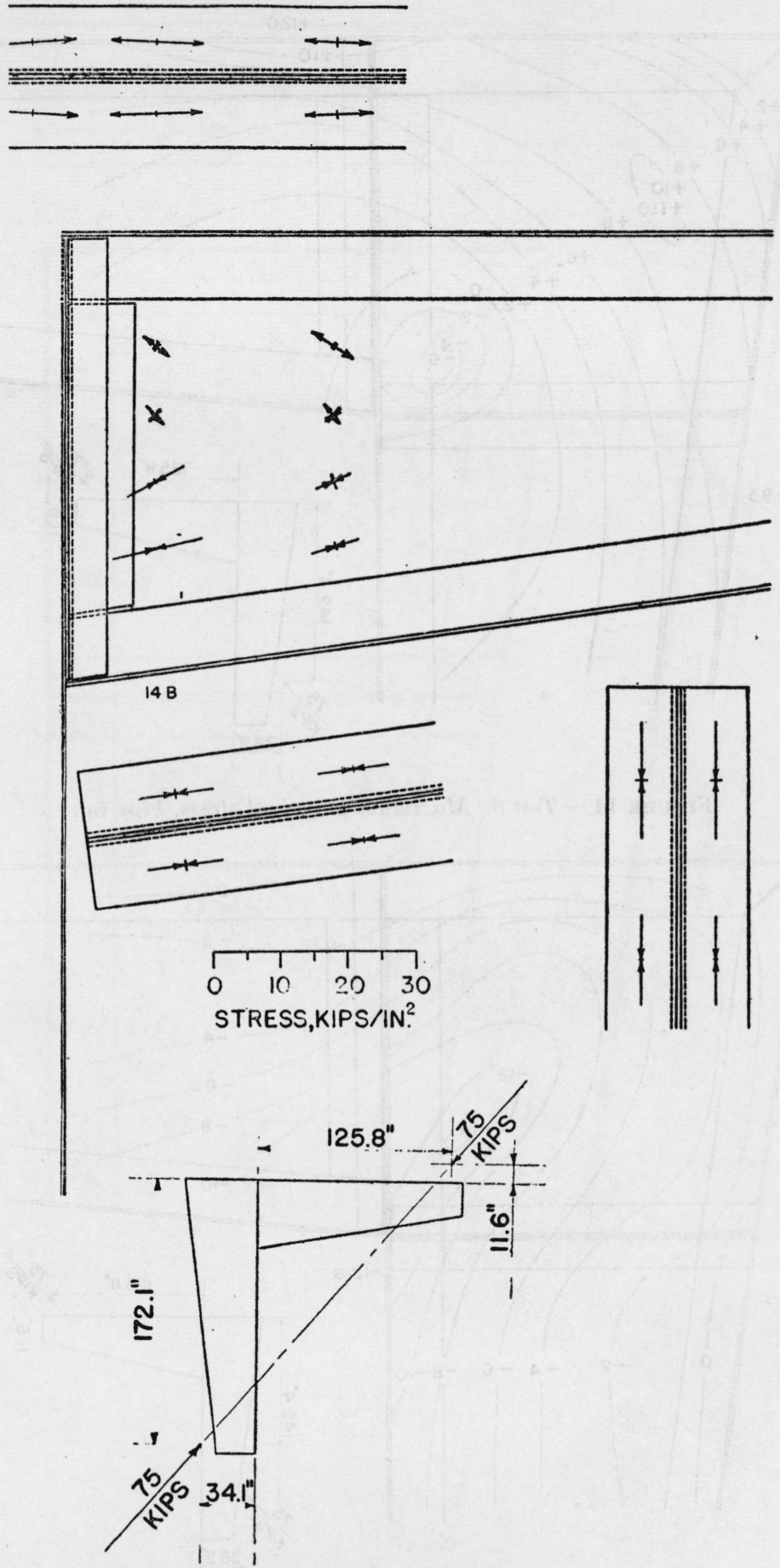

FIGURE 13.-Test 2. Magnitude and direction of the maximum and of the minimum principal stresses, kips/in². 


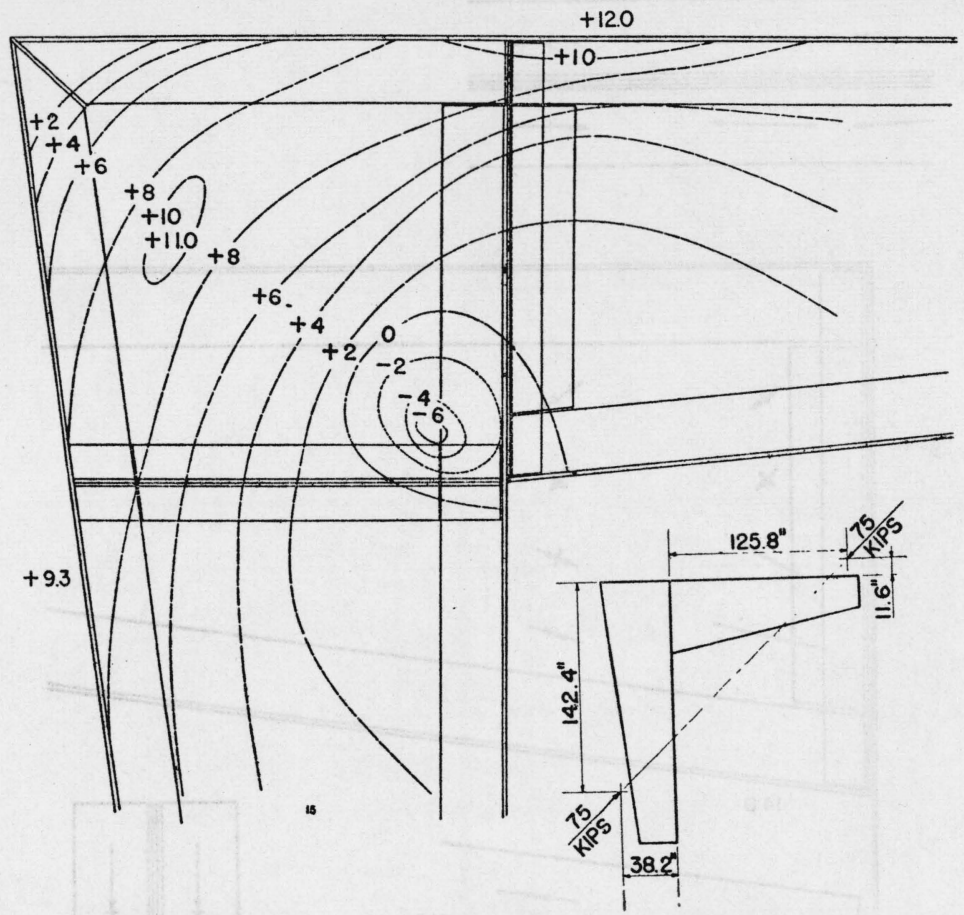

Figure 14.-Test 3. Maximum principal stress, kips/in².

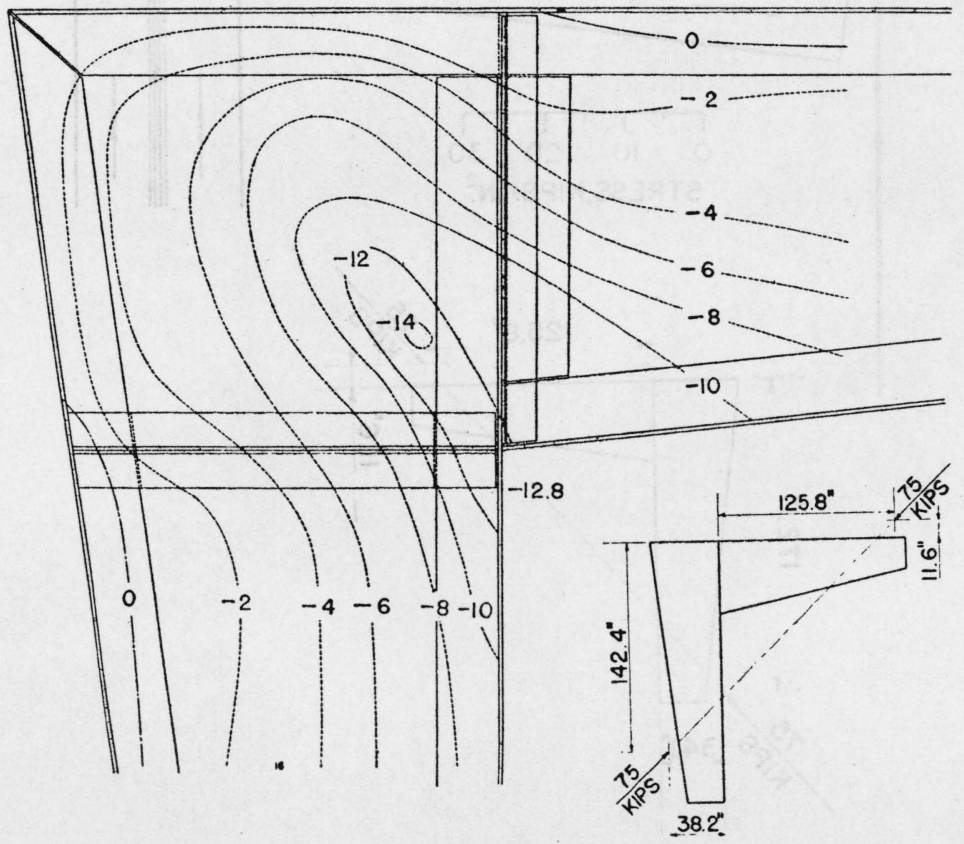

Figure 15.-Test 3. Minimum principal stress, kips/in². 


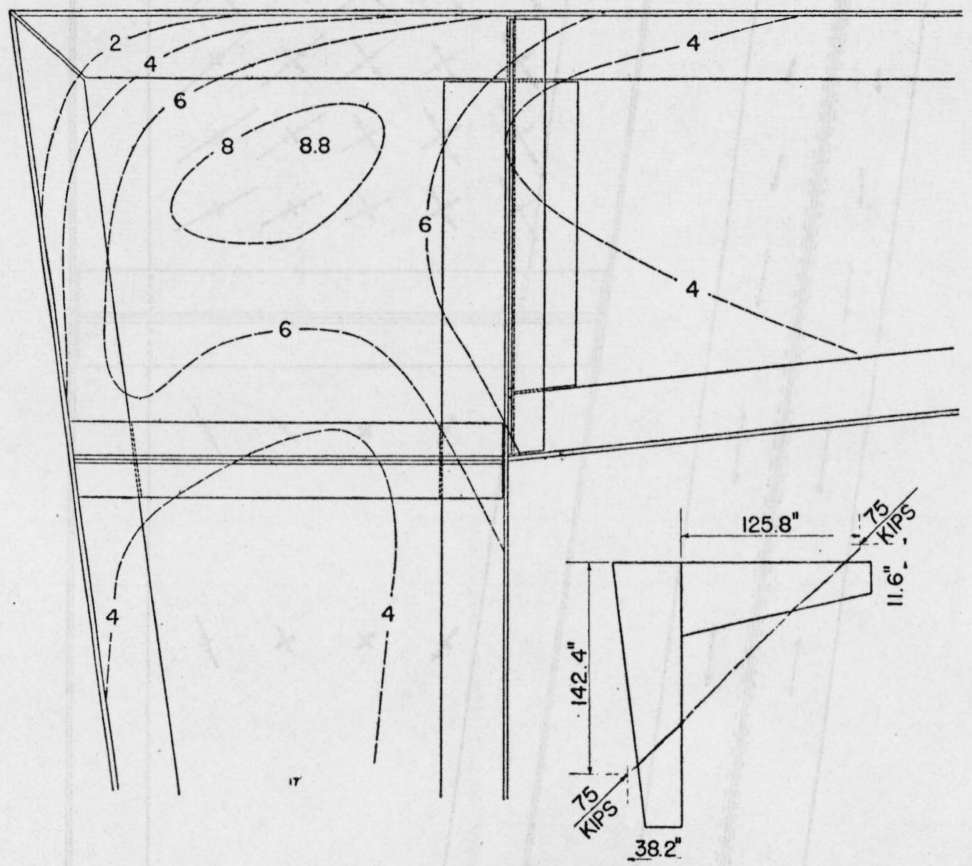

Figure 16.-Test 3. Maximum shearing stress, kips/in ${ }^{2}$. 

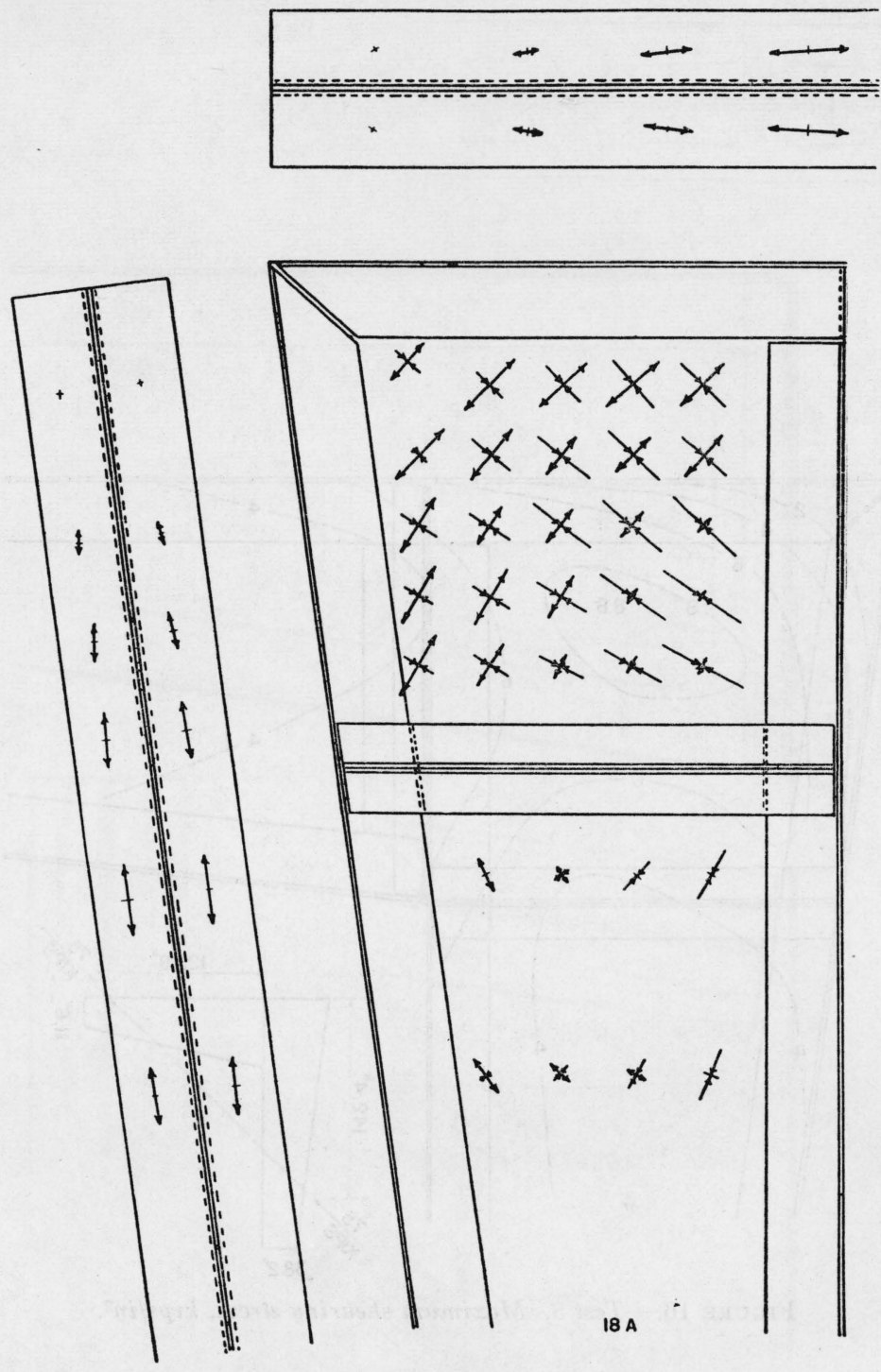

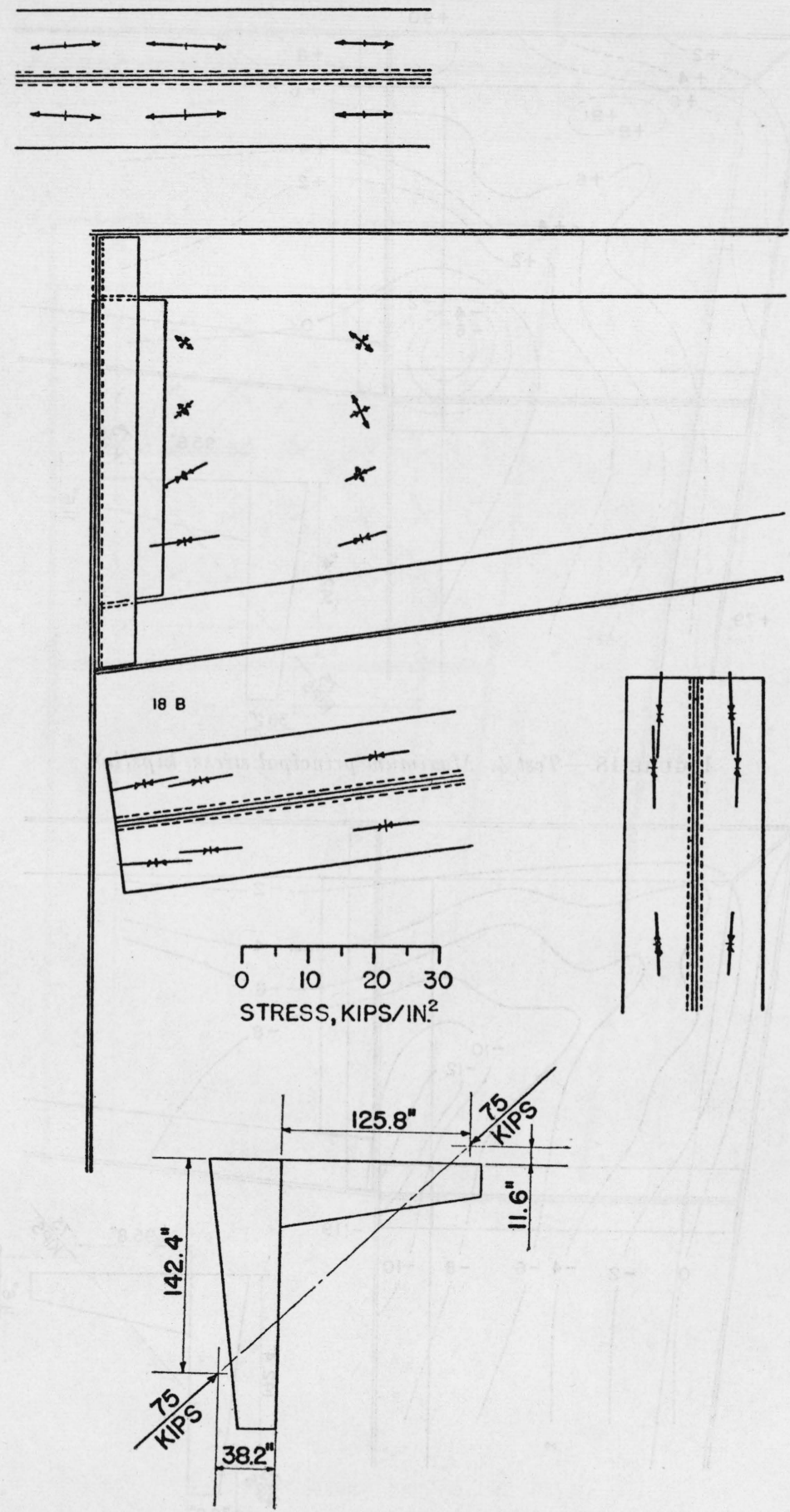

FIGURE 17.-Test 3. Magnitude and direction of the maximum and of the minimum principal stresses, kips $/$ in $^{2}$. 


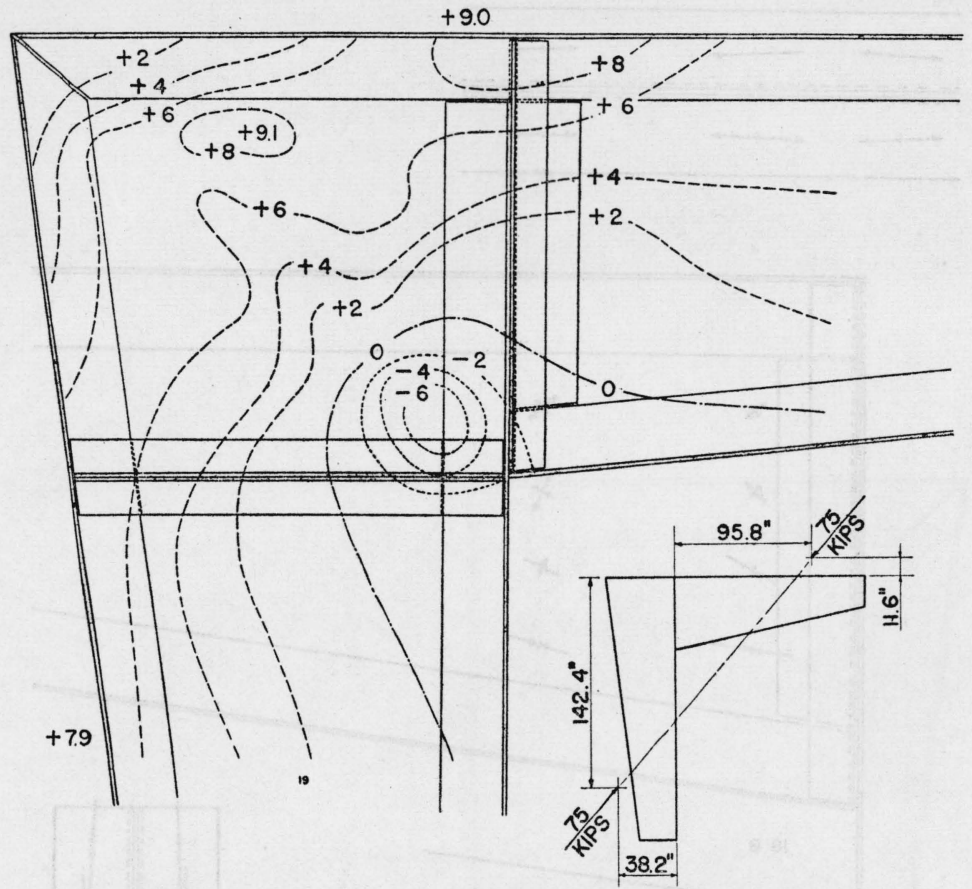

FigdRe 18.-Test 4. Maximum principal stress, kips/in².

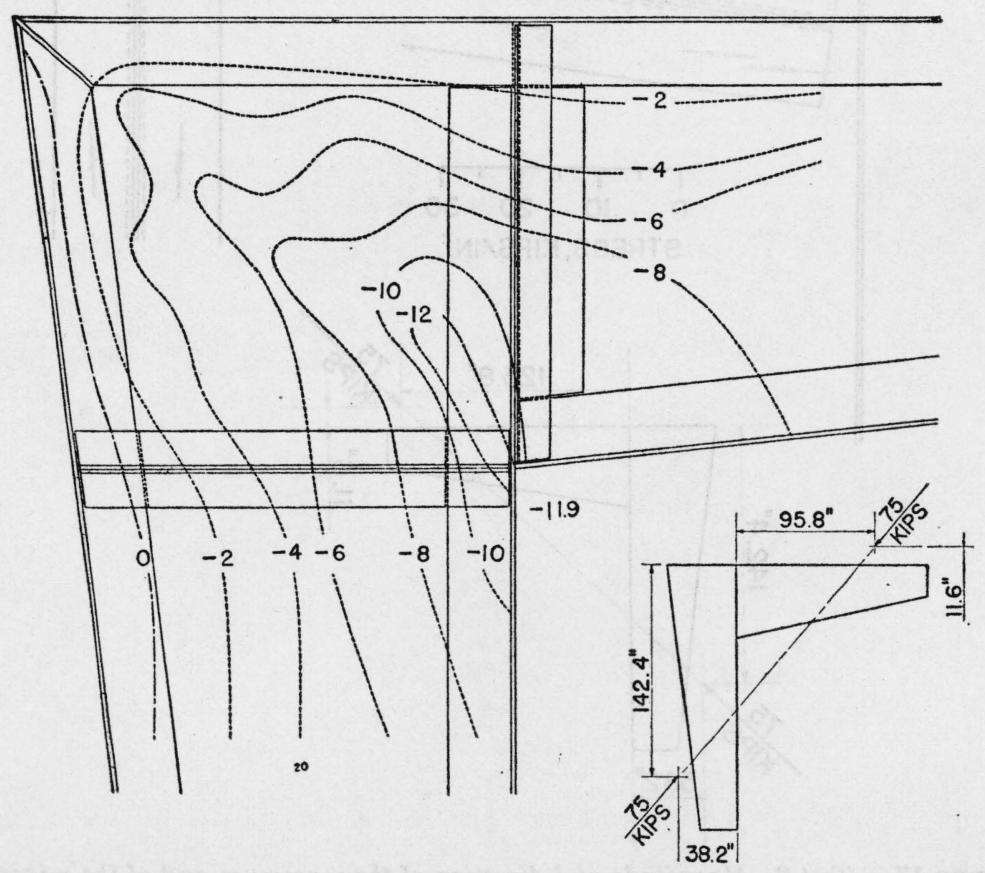

Figure 19.-Test 4. Minimum principal stress, kips/in ${ }^{2}$. 


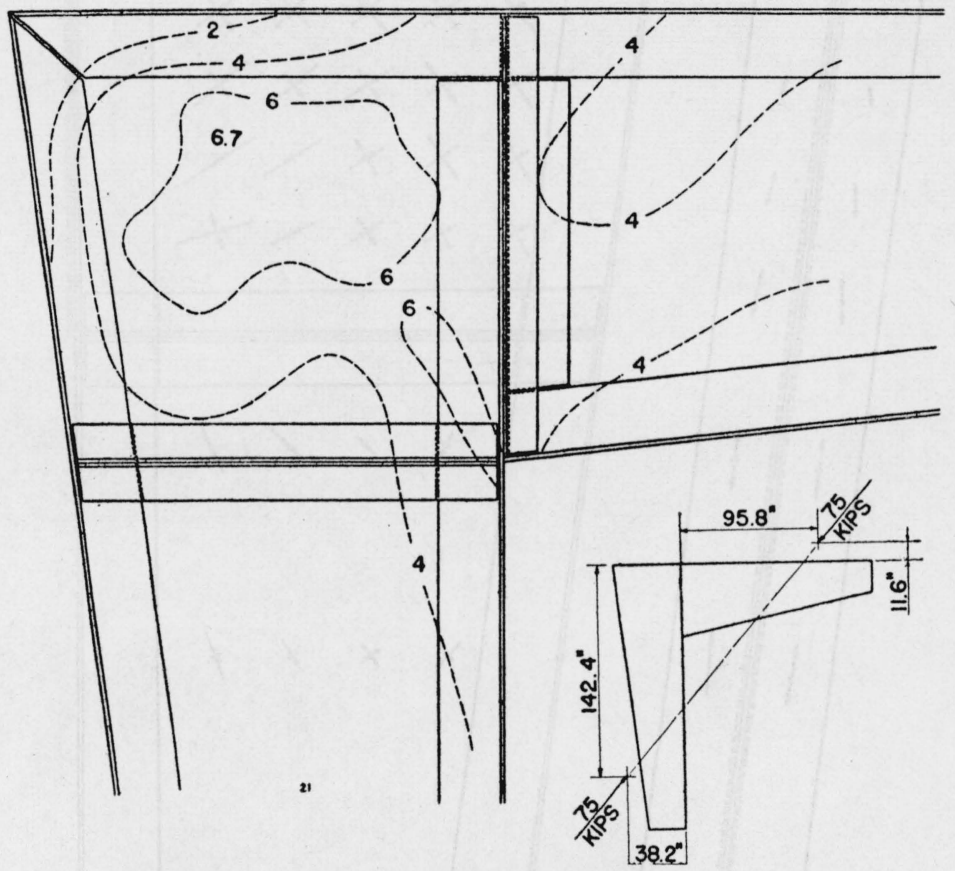

Figure 20.-Test 4. Maximum shearing stress, kips/in ${ }^{2}$. 


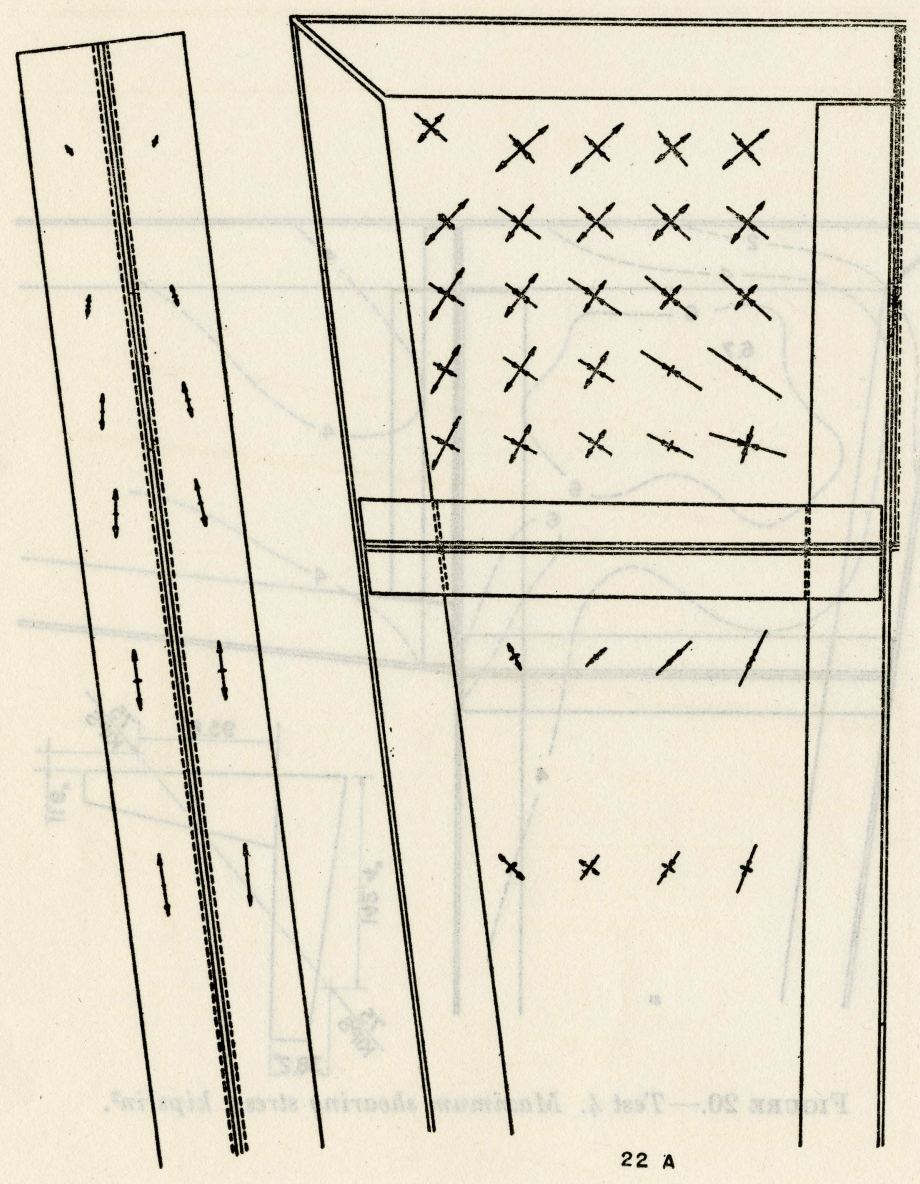



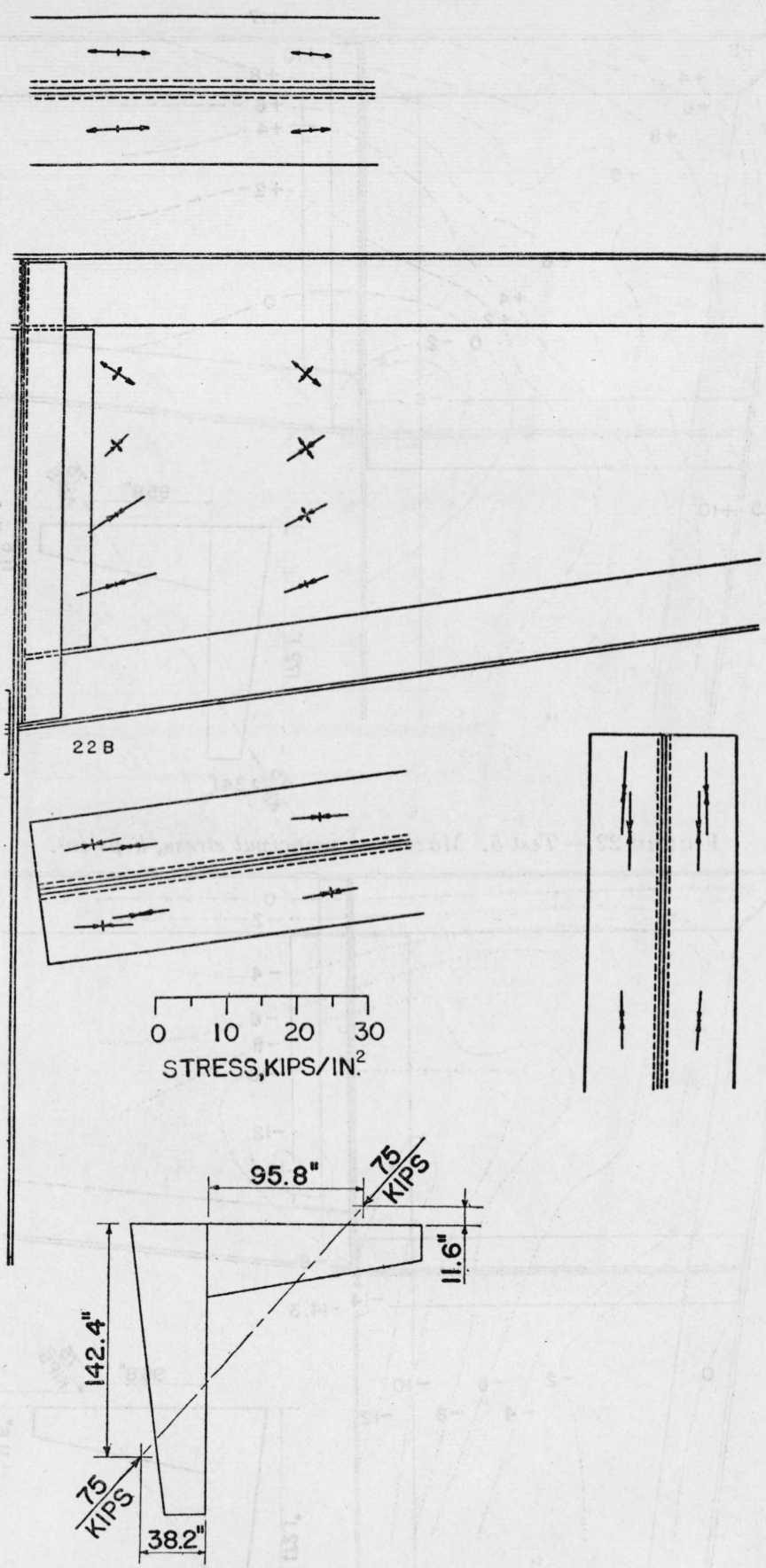

Figure 21.-Test 4. Magnitude and direction of the maximum and of the minimum principal stresses, kips/in ${ }^{2}$. 


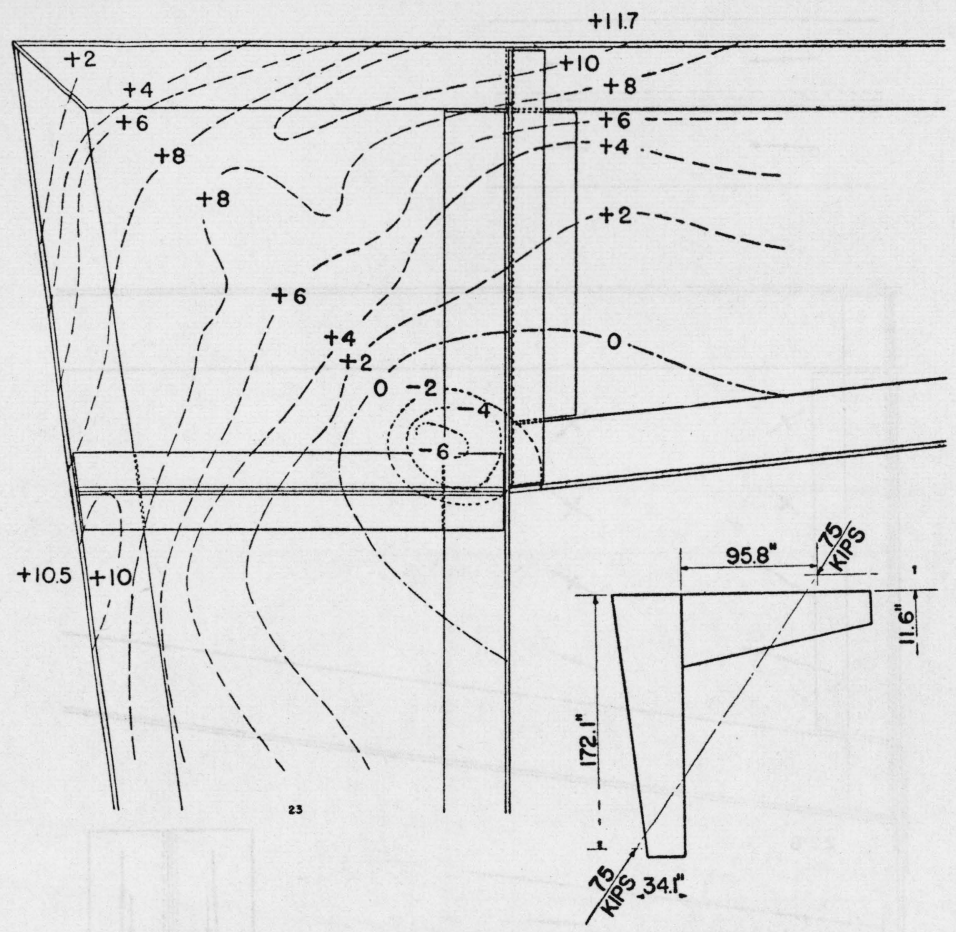

FIGURE 22.-Test 5. Maximum principal stress, kips/in².

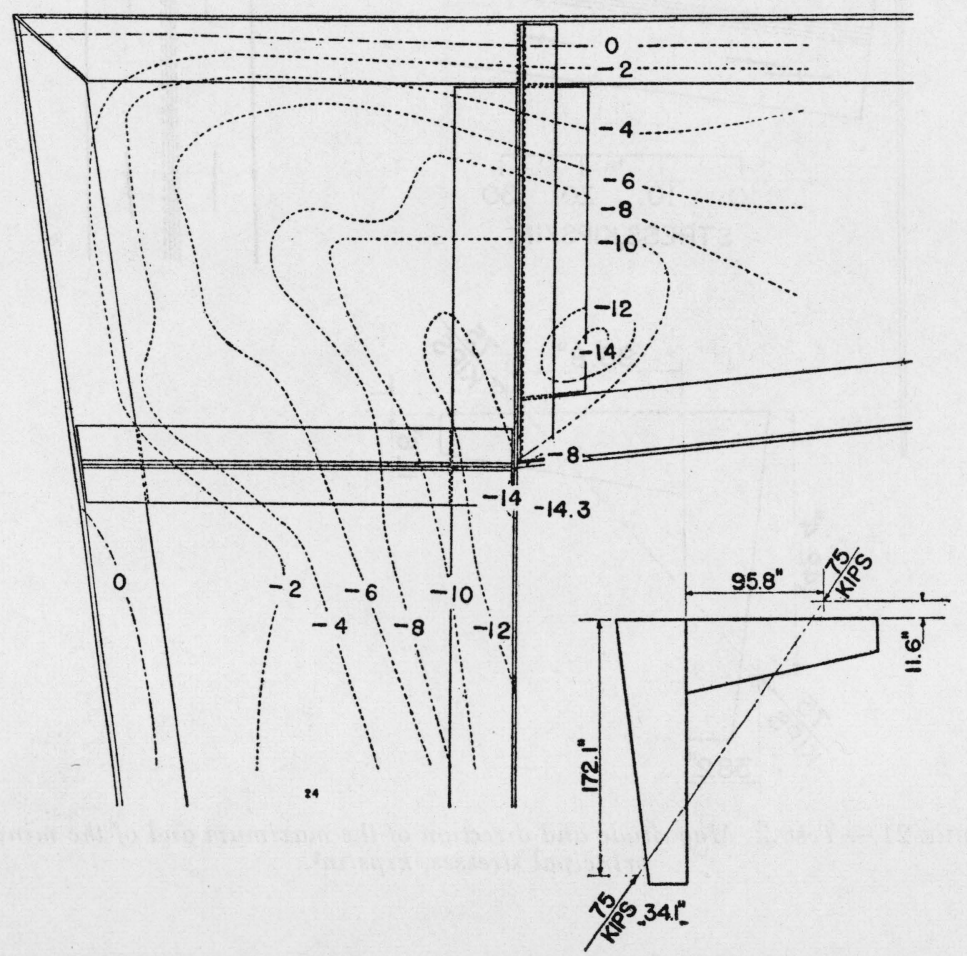

Frgure 23.-Test 5. Minimum principal stress, kips/in². 


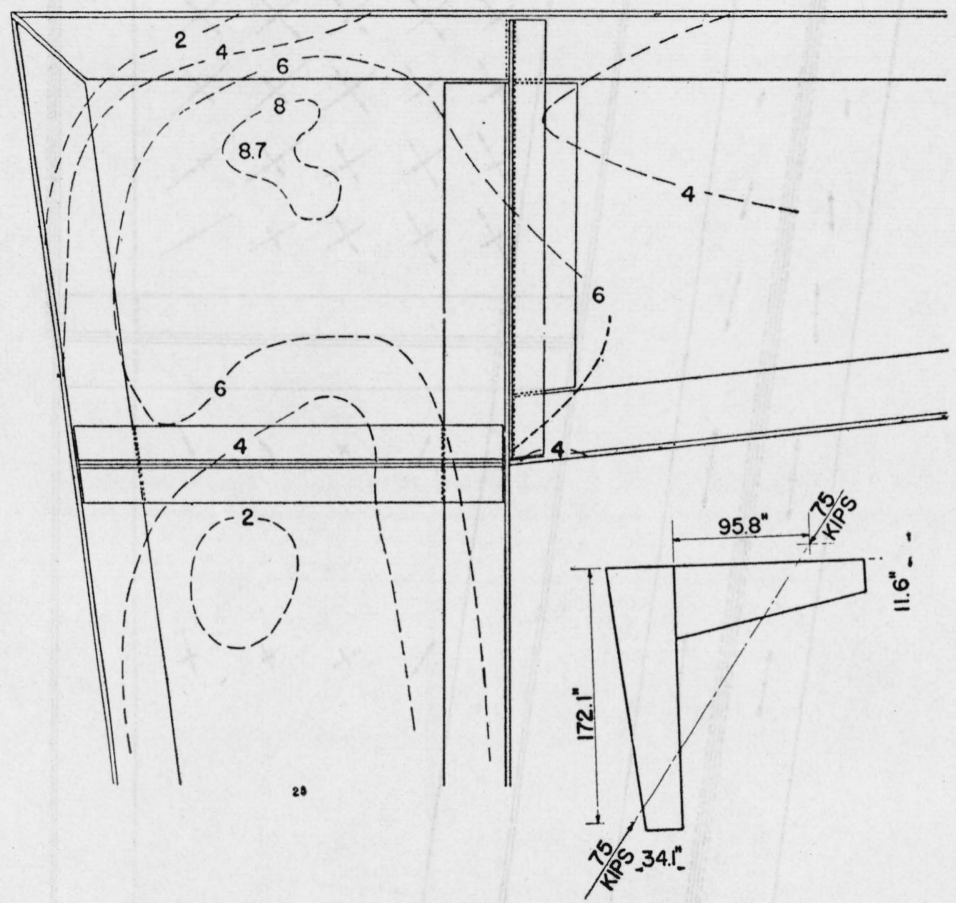

Figure 24.-Test 5. Maximum shearing stress, kips/in². 
Journal of Research of the National Bureau of Standards Vol.21]
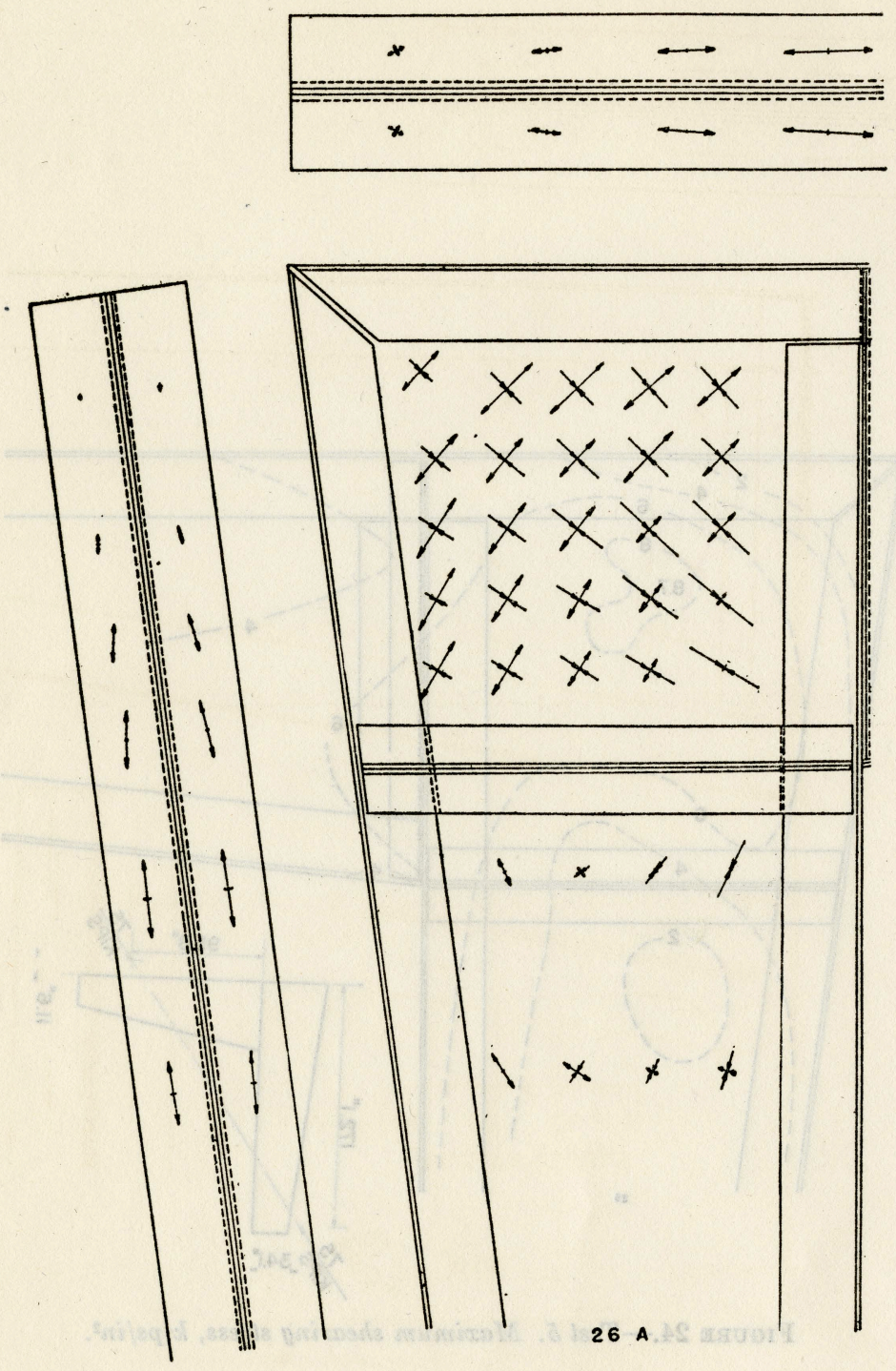

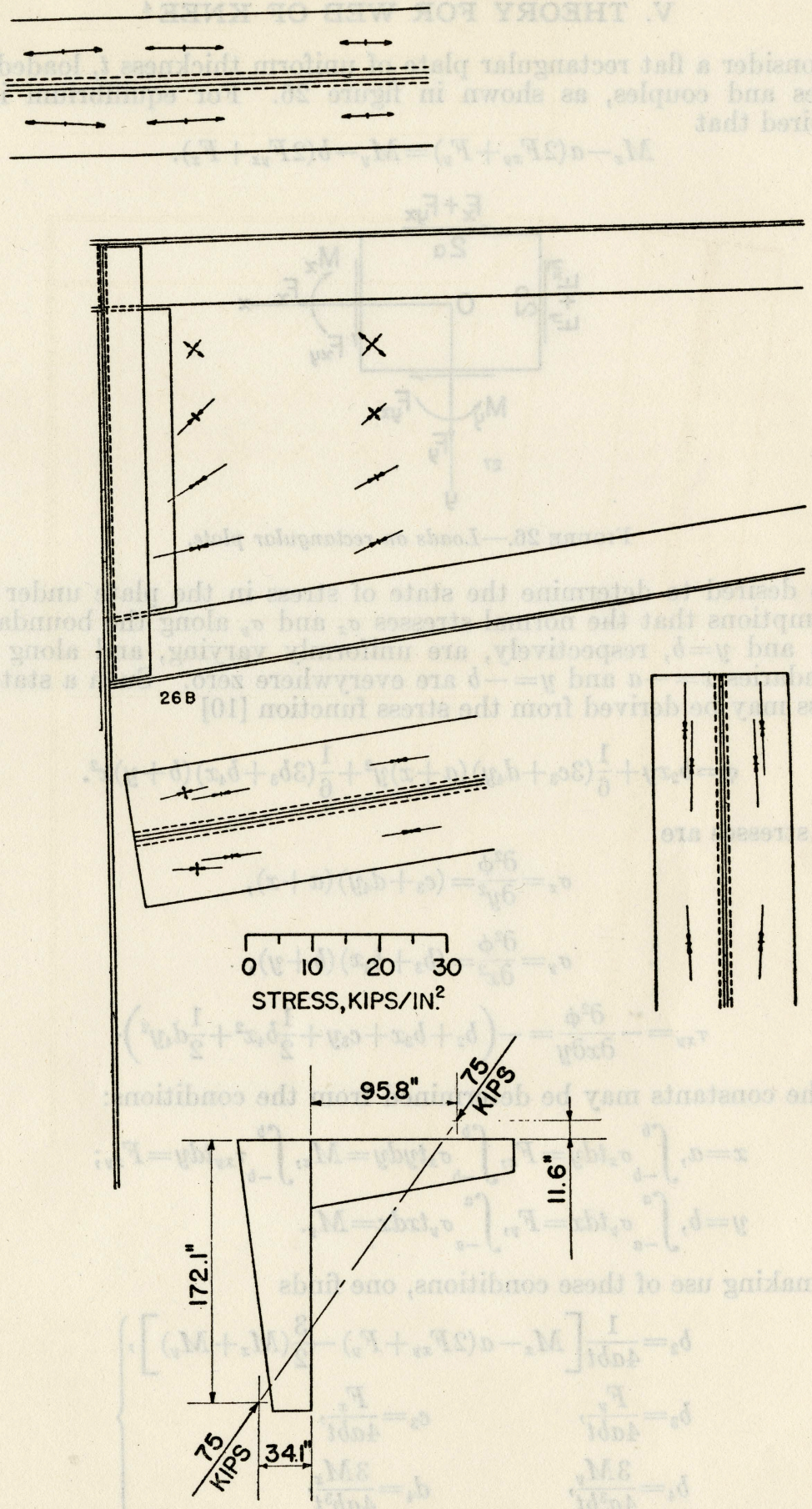

Figure 25.-Test 5. Magnitude and direction of the maximum and of the minimum principal stresses, kips/in'. 


\section{THEORY FOR WEB OF KNEE *}

Consider a flat rectangular plate of uniform thickness $t$, loaded by forces and couples, as shown in figure 26 . For equilibrium it is required that

$$
M_{x}-a\left(2 F_{x y}+F_{y}\right)=M_{y}-b\left(2 F_{y x}+F_{x}\right) .
$$

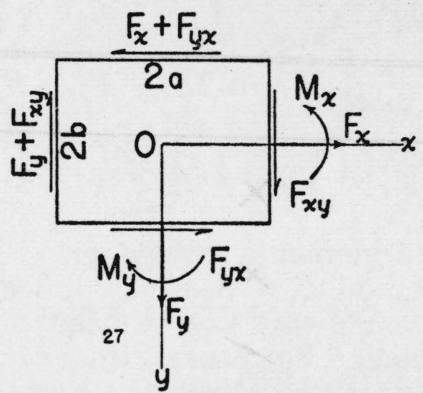

Figure 26.-Loads on rectangular plate.

It is desired to determine the state of stress in the plate under the assumptions that the normal stresses $\sigma_{x}$ and $\sigma_{y}$ along the boundaries $x=a$ and $y=b$, respectively, are uniformly varying, and along the boundaries $x=-a$ and $y=-b$ are everywhere zero. Such a state of stress may be derived from the stress function [10]

$$
\phi=b_{2} x y+\frac{1}{6}\left(3 c_{3}+d_{4} y\right)(a+x) y^{2}+\frac{1}{6}\left(3 b_{3}+b_{4} x\right)(b+y) x^{2} .
$$

The stresses are

$$
\begin{gathered}
\sigma_{x}=\frac{\partial^{2} \phi}{\partial y^{2}}=\left(c_{3}+d_{4} y\right)(a+x), \\
\sigma_{y}=\frac{\partial^{2} \phi}{\partial x^{2}}=\left(b_{3}+b_{4} x\right)(b+y), \\
\tau_{x y}=-\frac{\partial^{2} \phi}{\partial x \partial y}=-\left(b_{2}+b_{3} x+c_{3} y+\frac{1}{2} b_{4} x^{2}+\frac{1}{2} d_{4} y^{2}\right) .
\end{gathered}
$$

The constants may be determined from the conditions:

$$
\begin{aligned}
& x=a, \int_{-b}^{b} \sigma_{x} t d y=F_{x}, \int_{-b}^{b} \sigma_{x} t y d y=M_{x}, \int_{-b}^{b} \tau_{x y} t d y=F_{x y} \\
& y=b, \int_{-a}^{a} \sigma_{y} t d x=F_{y}, \int_{-a}^{a} \sigma_{y} t x d x=M_{y} .
\end{aligned}
$$

By making use of these conditions, one finds

$$
\left.\begin{array}{ll}
b_{2}=\frac{1}{4 a b t}\left[M_{x}-a\left(2 F_{x y}+F_{y}\right)-\frac{3}{2}\left(M_{x}+M_{y}\right)\right] \\
b_{3}=\frac{F_{y}}{4 a b t}, & c_{3}=\frac{F_{x}}{4 a b t}, \\
b_{4}=\frac{3 M_{y}}{4 a^{3} b t}, & d_{4}=\frac{3 M_{x}}{4 a b^{3} t}
\end{array}\right\}
$$

4 Since this theory was developed at the National Bureau of Standards, another was published in Germany [9]. 
Insertion in eq 2, 3, and 4 of the values found for the constants gives for the stresses

$$
\begin{aligned}
\sigma_{x}= & \frac{1}{4 a b t}\left(F_{x}+\frac{3 M_{x}}{b^{2}} y\right)(a+x), \\
\sigma_{y}= & \frac{1}{4 a b t}\left(F_{y}+\frac{3 M_{y}}{a^{2}} x\right)(b+y), \\
\tau_{x y}= & -\frac{1}{4 a b t}\left[M_{x}-a\left(2 F_{x y}+F_{y}\right)+F_{y} x+F_{x} y\right. \\
& \left.-\frac{3}{2} M_{y}\left(1-\frac{x^{2}}{a^{2}}\right)-\frac{3}{2} M_{x}\left(1-\frac{y^{2}}{b^{2}}\right)\right],
\end{aligned}
$$

in which the forces and moments satisfy eq 1 . It may be noted that along $x=a$ and $y=b, \sigma_{x}$ and $\sigma_{y}$, respectively, since they vary uniformly, are distributed in the same way as in a beam subjected to combined axial and flexural loading. For other values of $x$ and $y$ these stresses fall off linearly. Along these edges $(x=a, y=b)$ also the shearing stress represented by the last two terms in eq 8 varies parabolically, as in a beam in which the shearing force on a cross section has the value $M_{x} /(2 a)$ or $M_{y /}^{\prime}(2 b)$, respectively.

\section{THEORETICAL STRESSES}

In applying the theory to the web plate at the knee of a rigid frame it is necessary first to isolate the portion. of the web plate which is to be considered. If a flange is regarded as consisting of the two angles and a part of the web plate between them, figure 27, and if the stress in the flange is assumed to be uniformly distributed over the cross section, it is reasonable to take the boundary of the isolated portion of the web plate at the centroid of the cross-sectional area

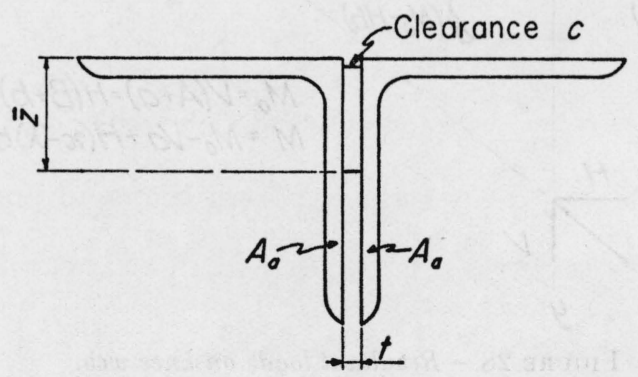

Figure 27.-Cross section of flange.

of the flange. That is, the boundary in question would be determined from the equation (Fig. 27)

$$
2 A_{a} z_{a}+\frac{t}{2}\left(\bar{z}^{2}-c^{2}\right)=\left[2 A_{a}+t(\bar{z}-c)\right] \bar{z}
$$

where $\bar{z}$ is the distance from the back of the angles to the centroid of the angles and the part of the web plate between the centroid and 
the outside edge, $z_{a}$ is the distance from the back of the angles to the centroid of the angles, and the other quantities are indicated clearly in figure 27. In most cases arising in practice, it would be sufficiently accurate to take the centroid of the flange as at the centroid of the two angles $\left(\bar{z}=z_{a}\right)$.

The forces and couples acting on the isolated portion of the web plate are shown in figure 28 for a load with horizontal and vertical components $H$ and $V$ acting on the rigid frame as indicated. $\alpha$ and $\gamma$ are the proportions of $V$ and the bending moment, respectively, which are carried by each flange of the lower leg at the edge $y=b$. If a flange is not wholly continuous at the knee, it will transmit stress only partially across the discontinuous section and will also upset the assumed linear distribution of normal stress at the boundary, as in the case of the lower flange of the specimen tested. This condition can be approximated by the theory by taking the forces and couples as shown at the right in figure 28. $\kappa$ and $\lambda$ are the proportions

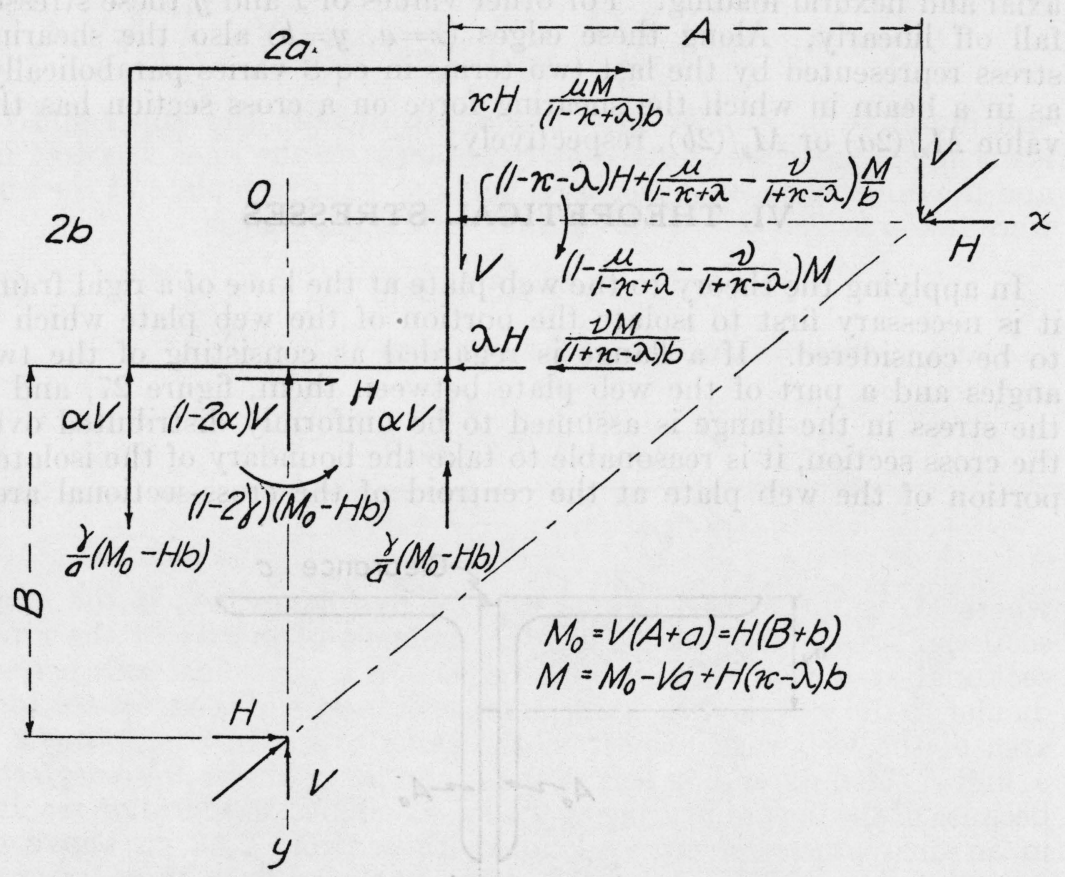

Figure 28.-Resultant loads on knee web.

of $H$, and $\mu$ and $\nu$ are the proportions of the bending moment which are carried by the outer and the inner flange, respectively, of the upper leg at the boundary $x=a$. If there had been no discontinuity, $\kappa$ would equal $\lambda$ and $\mu$ would equal $\nu$. It is assumed that the flanges carry no transverse shear. In terms of the forces and couples shown in figure 28 those shown in figure 26 become 


$$
\begin{aligned}
& F_{x}=-(1-\kappa-\lambda) H-\left(\frac{\mu}{1-\kappa+\lambda}-\frac{\nu}{1+\kappa-\lambda}\right) \frac{M}{b} \\
& F_{y}=-(1-2 \alpha) V \\
& F_{x y}=V-\alpha V-\frac{\gamma}{a}\left(M_{0}-H b\right) \\
& F_{y x}=H-\lambda H-\frac{\nu M}{(1+\kappa-\lambda) b} \\
& M_{x}=-\left(1-\frac{\mu}{1-\kappa+\lambda}-\frac{\nu}{1+\kappa-\lambda}\right) M \\
& M_{y}=-(1-2 \gamma)\left(M_{0}-H b\right) .
\end{aligned}
$$

In applying the theory to the knee of the rigid-frame specimen tested, $\bar{z}$ was computed for the two 6 - by 6 - by $\frac{3 / 8}{8}$-in. angles and part of the included $3 / 8$-in. plate from the equation

$$
2(4.36)(1.64)+\frac{3}{16}\left(\bar{z}^{2}-\frac{1}{16}\right)=\left[2(4.36)+\frac{3}{8}\left(\bar{z}-\frac{1}{4}\right)\right] \bar{z}
$$

and found to be $\bar{z}=1.60$ in. The depth of both the upper and the lower leg of the frame immediately adjacent to the knee was $40 \frac{1}{2}$ in., and the dimensions of the isolated portion of the web plate at the knee were taken as $2 a=2 b=40.5-2(1.60)=37.3$ in., that is,

$$
a=b=18.65 \text { in. }
$$

$\alpha$ and $\gamma$ were obtained from the relations

$$
\left.\begin{array}{l}
\alpha=\frac{A_{f}}{2 A_{f}+A_{w}}=\frac{9.23}{32.44}=.285, \\
\gamma=\frac{I_{f}}{2 I_{f}+I_{w}}=\frac{3209}{8040}=.399,
\end{array}\right\}
$$

where $A_{f}$ is the cross-sectional area of one flange, $A_{w}$ is the crosssectional area of the web, $I_{f}$ is the moment of inertia of the crosssectional area of one flange with respect to a centroidal axis perpendicular to the web, and $I_{w}$ is the moment of inertia of the cross-sectional area of the web with respect to the same axis. In computing $\kappa, \lambda$, $\mu$, and $\nu$, the outstanding legs of the inner flange angles were neglected because of the lack of bearing at the knee. This consideration resulted in an unsymmetrical cross section with centroid 2.93 in. above the axis of $x$, figure 28 . $\kappa, \lambda, \mu$, and $\nu$ were obtained from the relations

$$
\left.\begin{array}{l}
\kappa=\frac{A_{o}}{A_{o}+A_{i}+k A_{w}}=\frac{9.23}{26.82}=.344, \\
\lambda=\frac{A_{i}}{A_{o}+A_{i}+k A_{w}}=\frac{5.01}{26.82}=.187, \\
\mu=\frac{I_{o}}{I_{o}+I_{i}+k I_{v}}=\frac{2280}{6179}=.369, \\
\nu=\frac{I_{i}}{I_{o}+I_{i}+k I_{v}}=\frac{2331}{6179}=.377,
\end{array}\right\}
$$


where $A_{o}, A_{i}$, and $A_{v}$ are the cross-sectional areas of the outer flange, the inner flange, and the web, respectively, $I_{0}, I_{i}$, and $I_{20}$ are the moments of inertia of the cross-sectional areas of the outer flange, the inner flange, and the web, respectively, with respect to a centroidal axis perpendicular to the web, and $k$ is the relative stiffness of the splice compared to that of the solid plate. A value of $k=0.9$ was arbitrarily assumed in the computations of eq 10. A value of $k=0$ would correspond to a gap in the web, that is, all of the bending moment and axial load would be transmitted through the flanges. A value of $k=1$ would correspond to a solid web, that is, the bending moment and axial load would be transmitted as in an ordinary beam.

With the values of $a=b, \alpha, \gamma, \kappa, \lambda, \mu$, and $\nu$ given in eq 11, 12, and 13, eq 10 and 6,7 , and 8 were solved for the stresses for the four cases of loading corresponding to tests $2,3,4$, and 5 . The values of the measured stresses and of the theoretical stresses are shown in figures $29,30,31$, and 32 . The measured stresses are given by the arrows and the theoretical stresses by the curves.

The theoretical stresses in the legs were computed from the ordinary beam theory for a beam subjected to combined axial and flexural loading. According to this theory, the normal stress at any point of a cross section is given by

$$
\sigma_{n}=\frac{P}{A}+\frac{M l}{I},
$$

where $l$ is the distance of the point from the centroidal axis of the cross section perpendicular to the plane of bending, measured positive toward the outer flange; $A$ is the area of the cross section; $I$ is the moment of inertia of the cross section with respect to the centroidal axis; $P$ is the component of load normal to the cross section, positive when it produces tension; and $M$ is the bending moment at the cross section, positive when it produces tension on the outer side of the centroidal axis. by

The shearing stress at a distance $l$ from the centroidal axis is given

$$
\tau=\frac{F Q}{I p},
$$

where $F$ is the total transverse shear on the section, positive when the portion of the leg between the section and the outer end tends to slide in the direction of the other leg; $p$ is the width of the section at $l$; and $Q$ is the moment about the centroidal axis of the area of the portion of the section between $l$ and the extreme fiber.

In the ordinary beam theory the normal stress on any plane perpendicular to the cross section is zero.

In computing the stresses by formulas 14 and 15 , the sections were taken perpendicular to the outer flange of the upper leg and the inner flange of the lower leg. The sections were taken as symmetrical about a point midway between the extreme fibers, the obliquity of one flange to the section being neglected. The gross section was used in the computations [11].

The agreement between the theoretical and measured stresses in the lower leg is very close, especially for the normal stresses. In the upper 
leg near the knee very high normal stresses were developed in the web, and correspondingly low ones in the flange. This is undoubtedly due to the lack of bearing of the inner (compression) angles at the inner corner, explained in section II. These high stresses extend into the web of the knee and undoubtedly account for a considerable part of the discrepancy between the measured stresses and the theoretical stresses, for the assumptions of the theory concerning the loading of the edges of the plate are not fulfilled. The agreement between the theoretical and measured shearing stresses in the web of the knee is very close, and the shearing stresses seem to have been very little affected by the lack of bearing of the compression angles at the inner corner. 

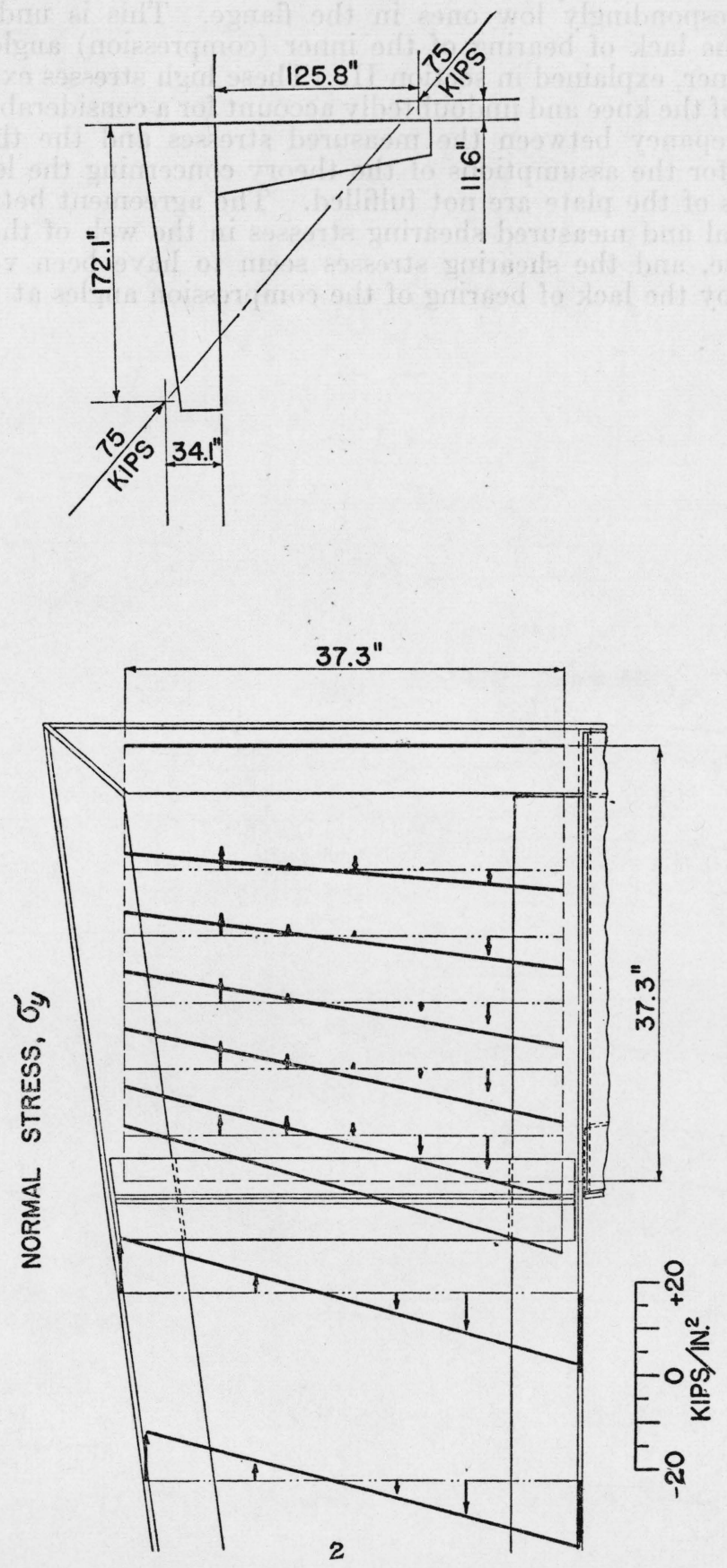
NORMAL STRESS, $\sigma_{\lambda}$

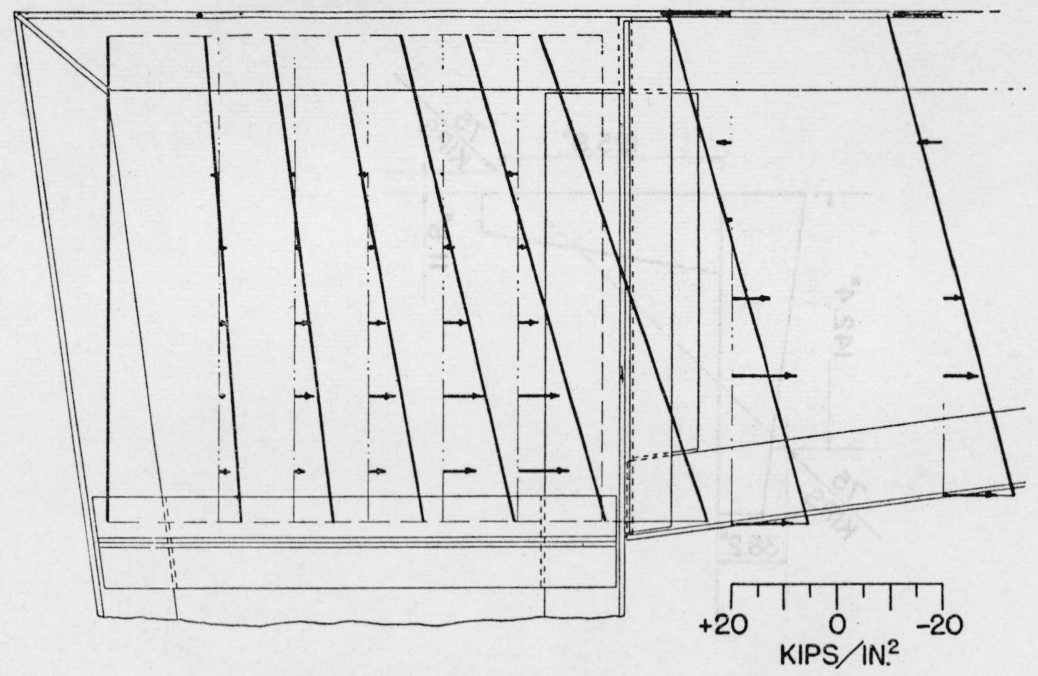

SHEARING STRESS, $\tau_{x y}$

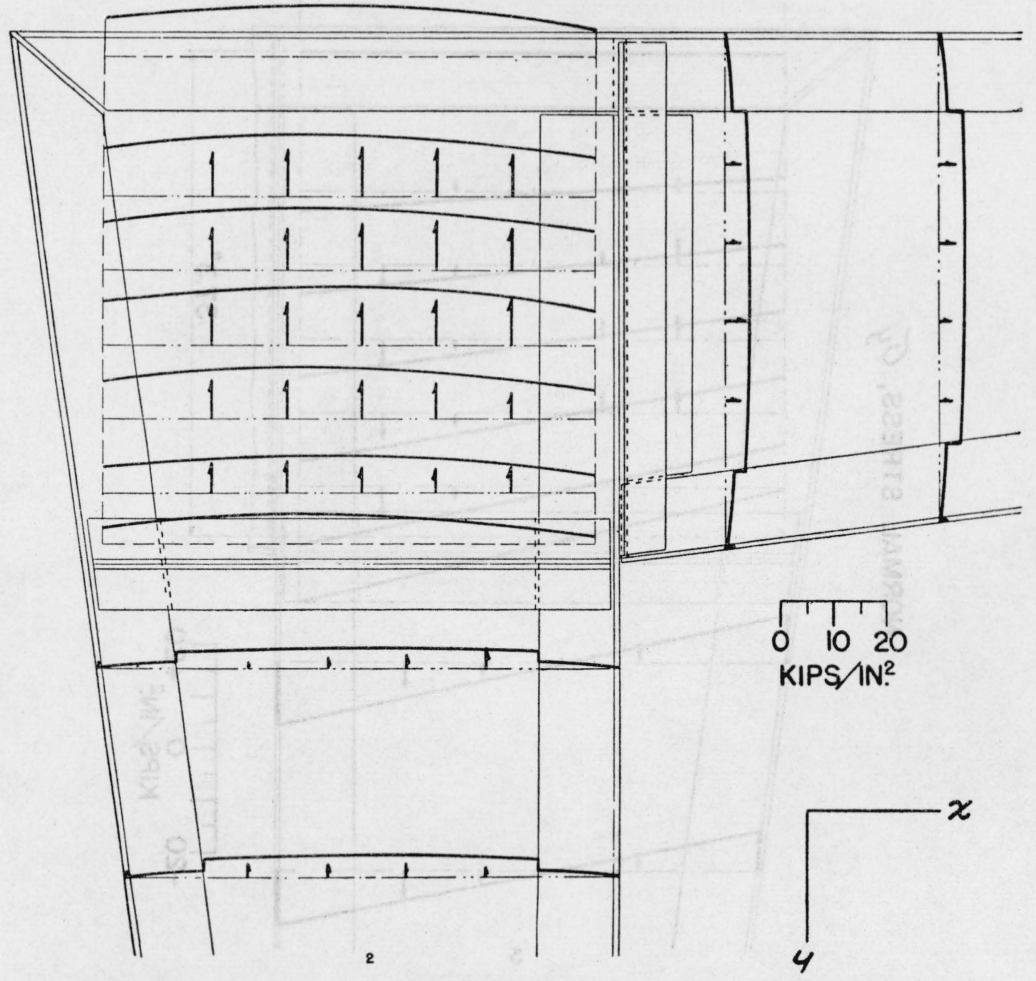

FigURE 29.-Test 2. Theoretical stresses and measured stresses. The curves represent theoretical, and the arrows measured, stresses. 

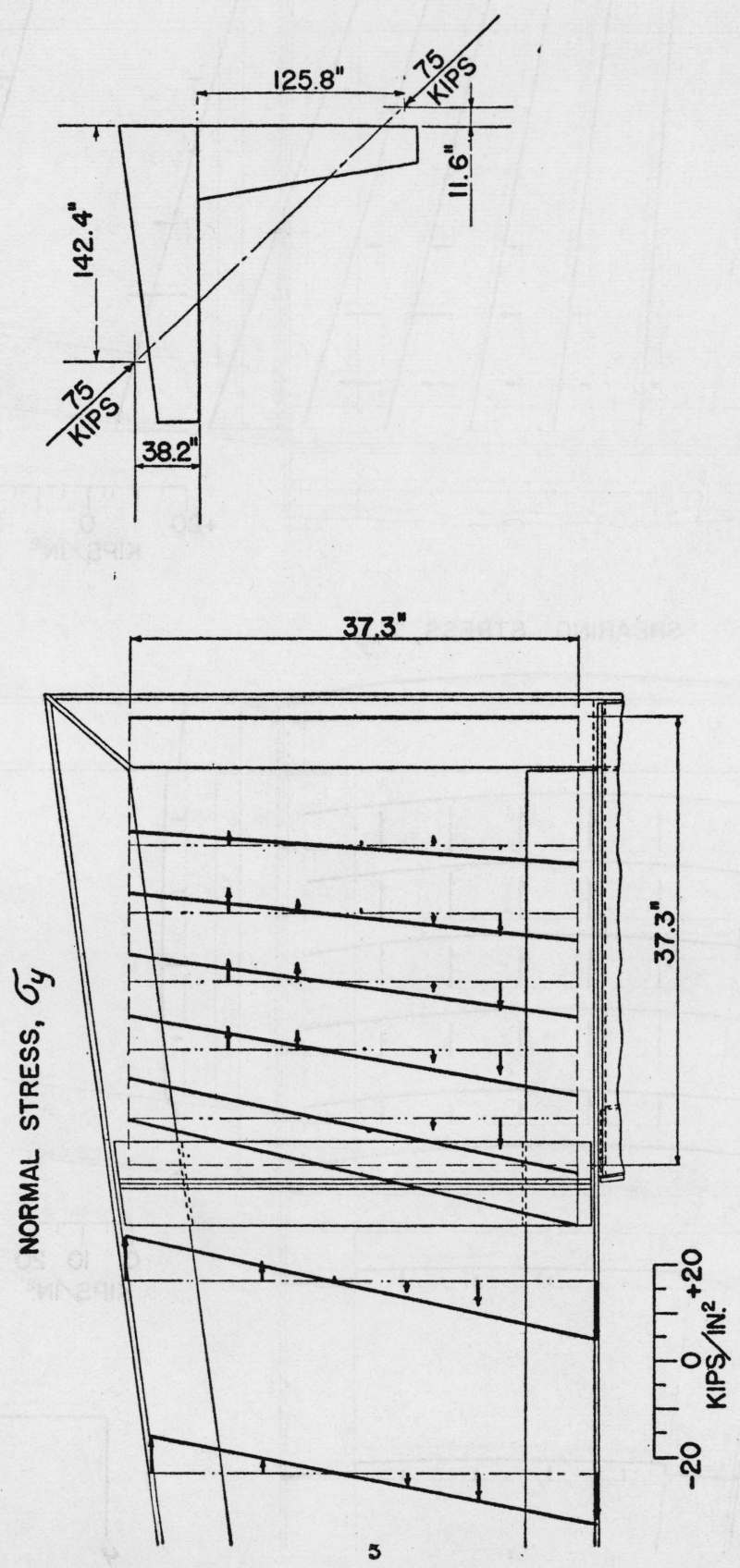
NORMAL STRESS, $\sigma_{x}$

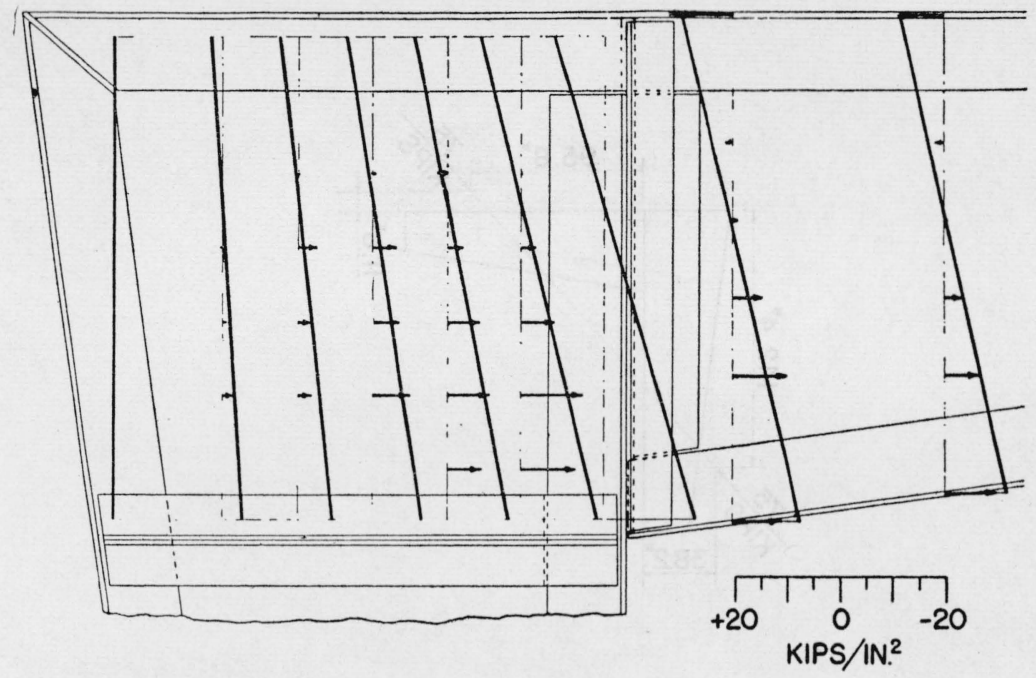

\section{SHEARING STRESS, $\tau_{x y}$}

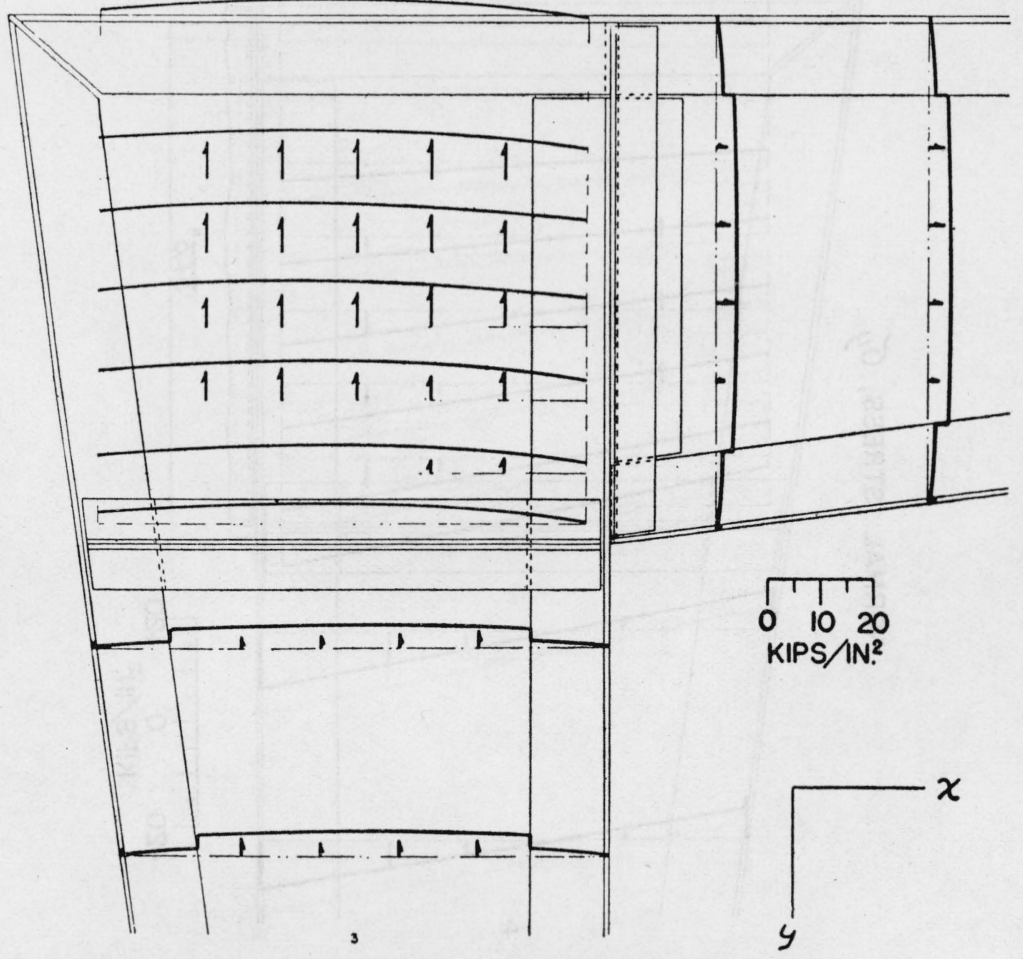

Figure 30.-Test 3. Theoretical stresses and measured stresses. The curves represent theoretical, and the arrows measured, stresses. 

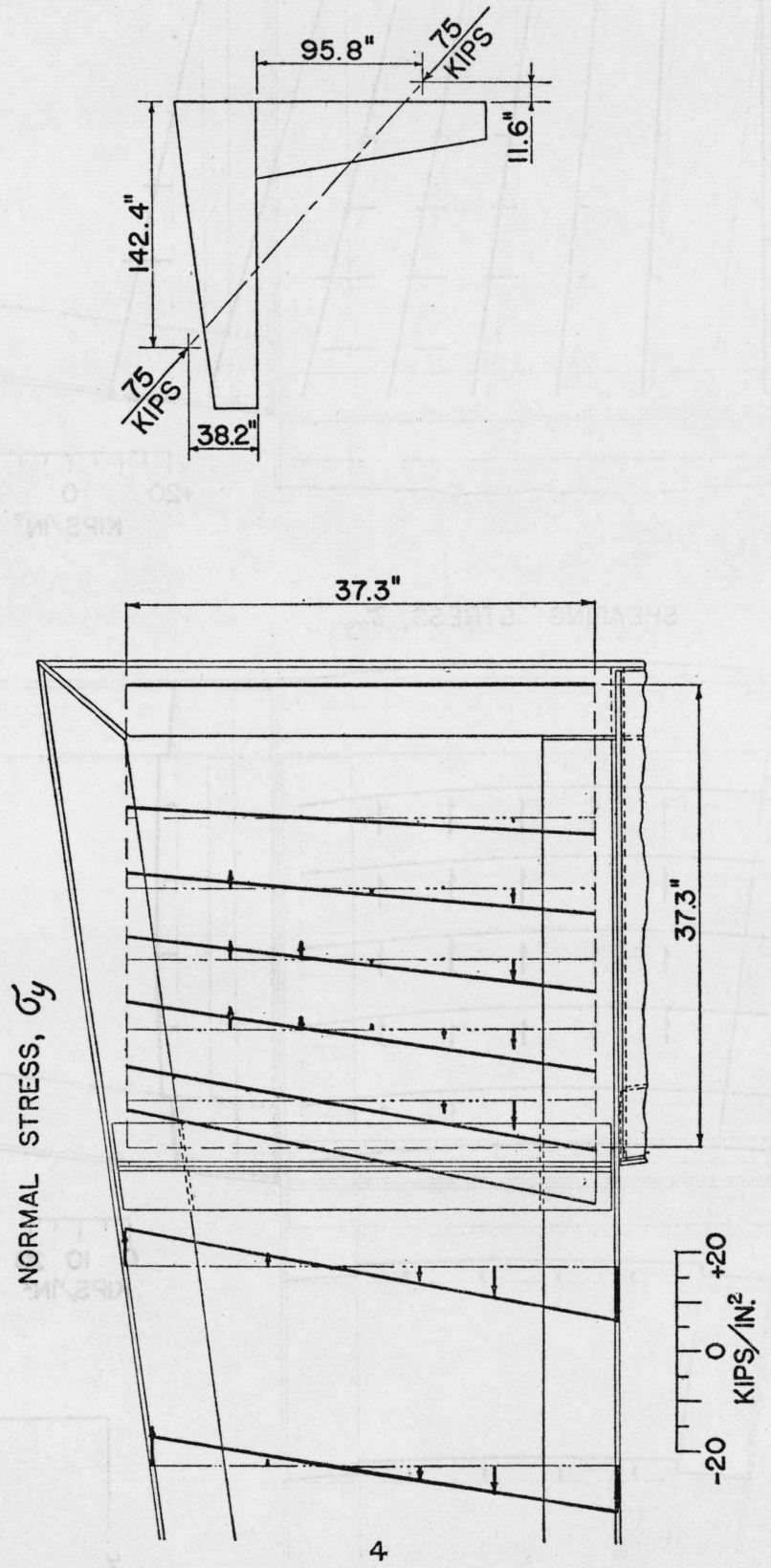
NORMAL STRESS, $\sigma_{x}$

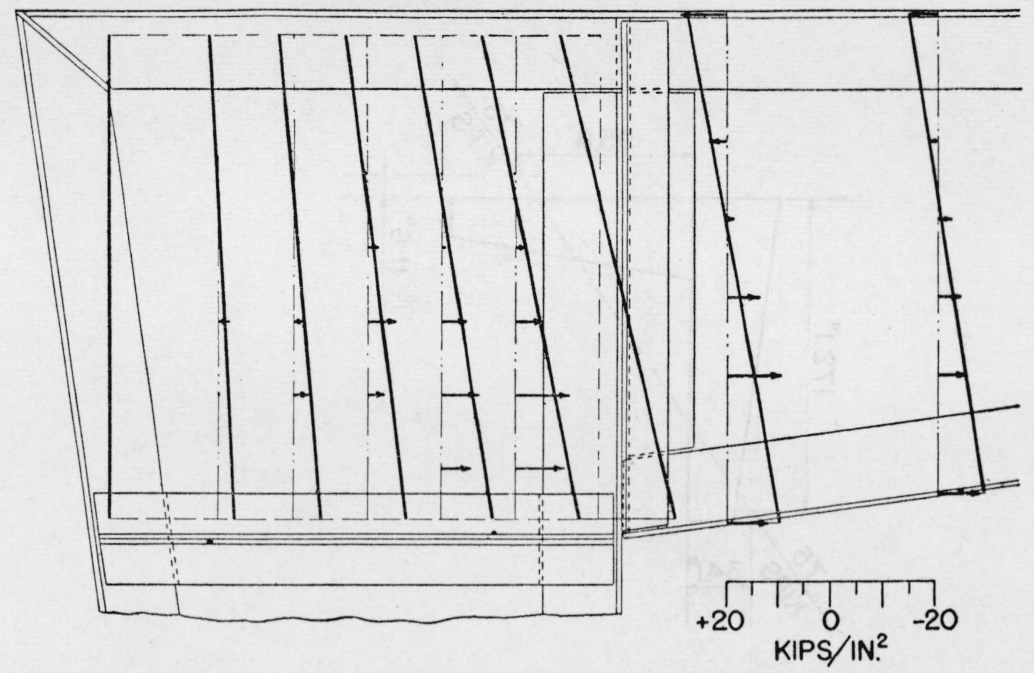

SHEARING STRESS, $\tau_{x y}$

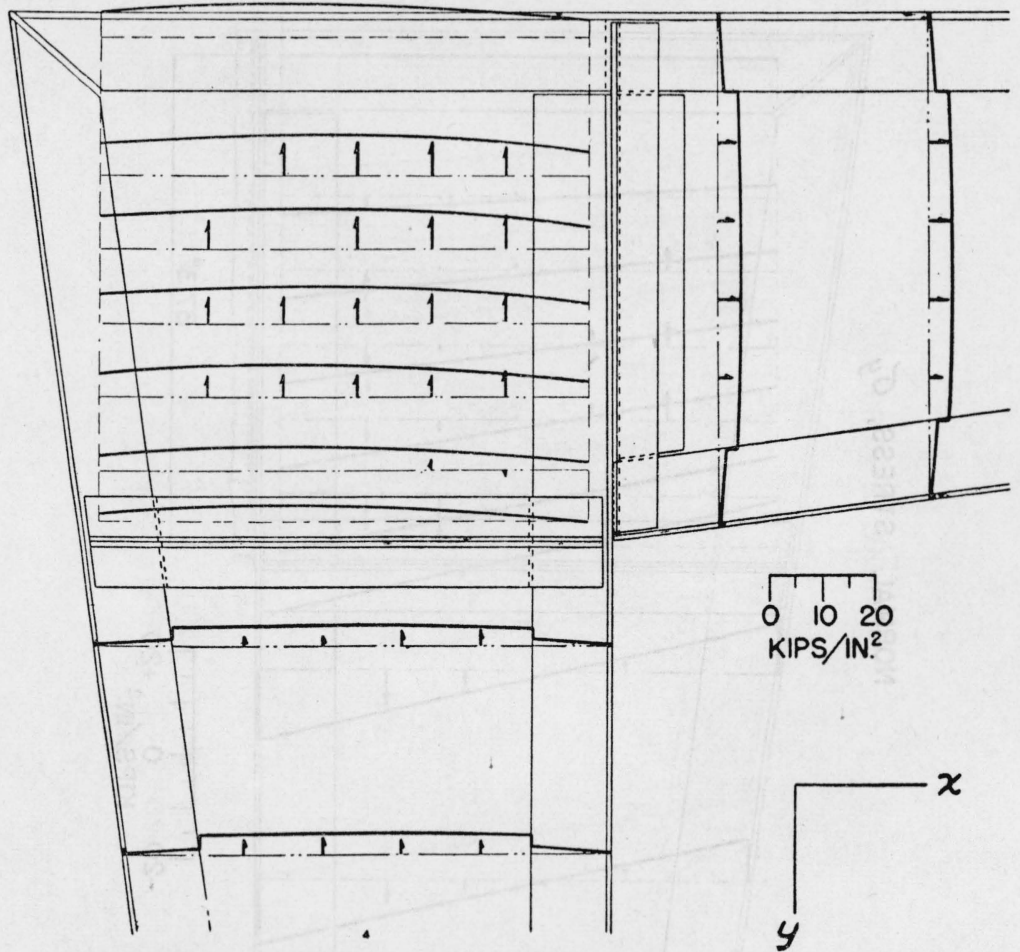

Figure 31.-Test 4. Theoretical stresses and measured stresses. The curves represent theoretical, and the arrows measured, stresses. 

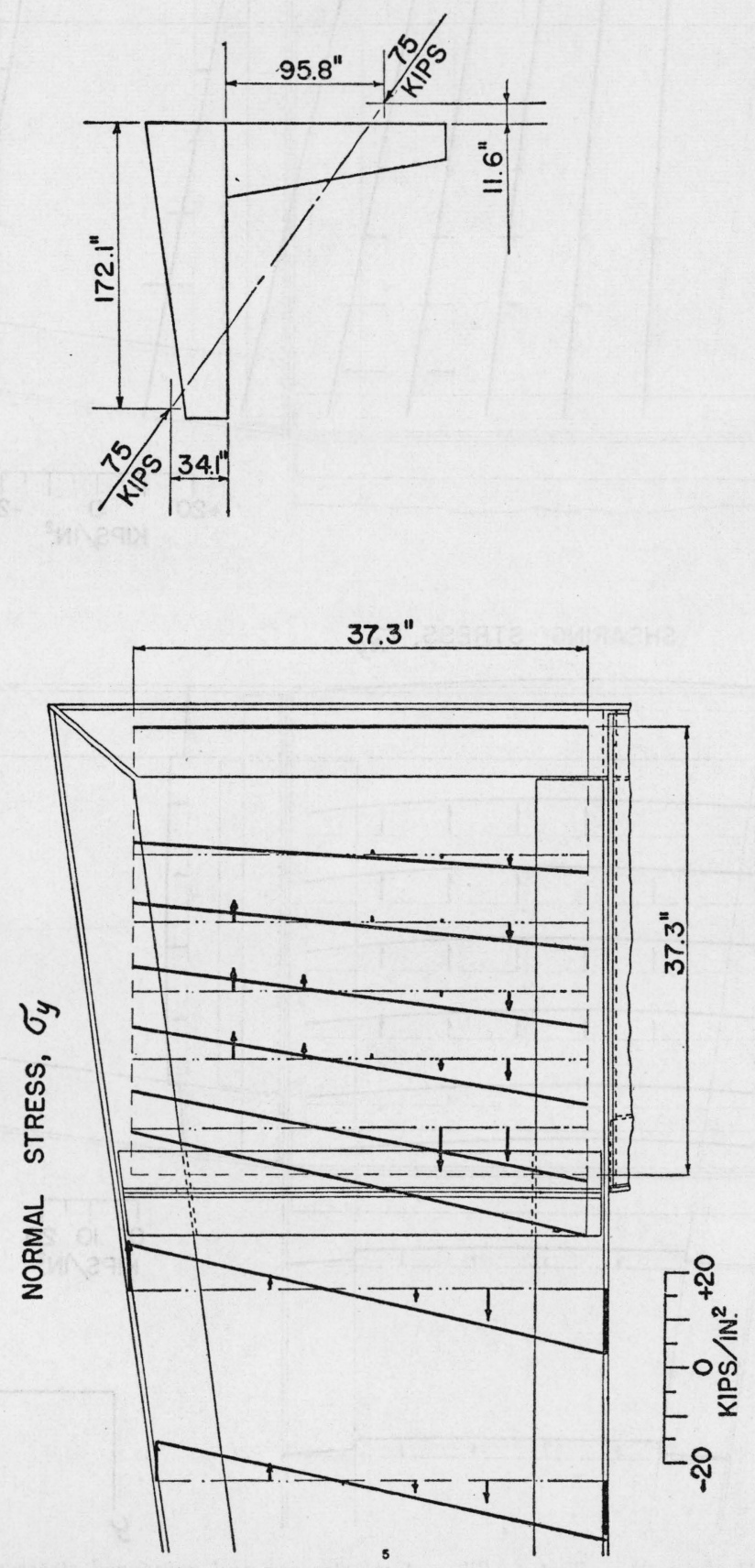
NORMAL STRESS, $\sigma_{x}$

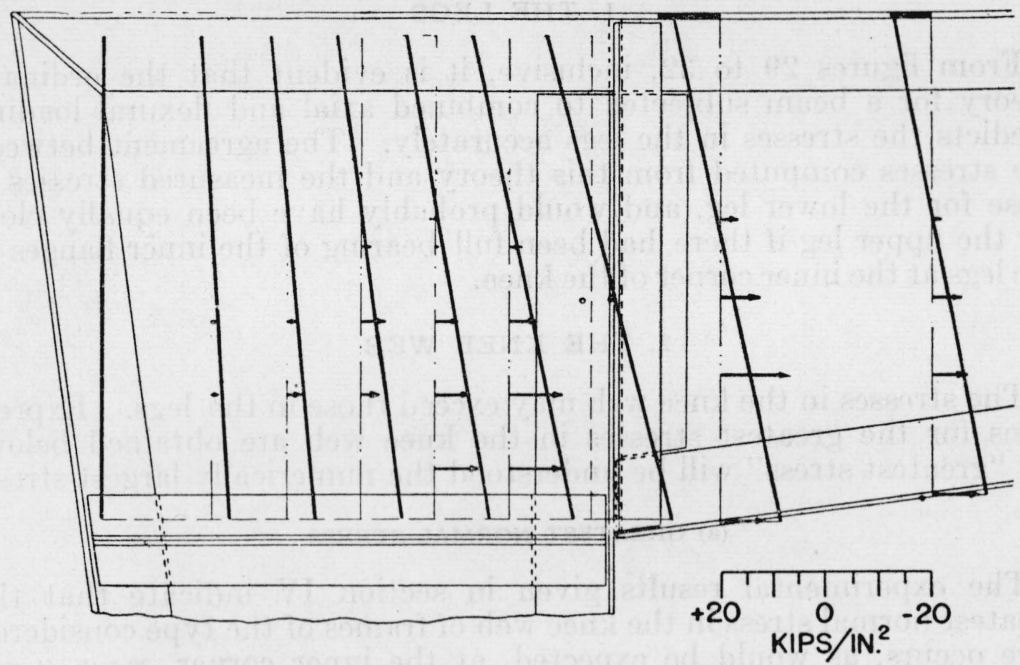

SHEARING STRESS, $\tau_{x y}$

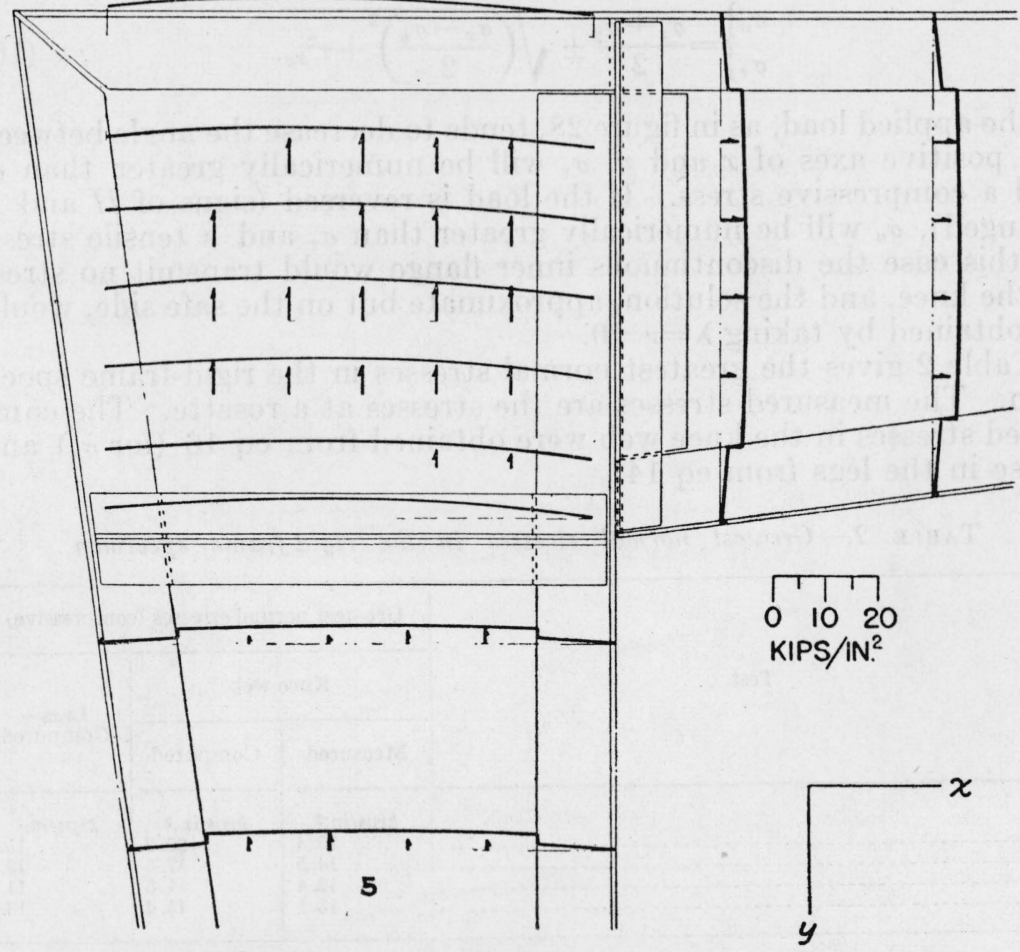

Figure 32.-Test 5. Theoretical stresses and measured stresses.

The curves represent theoretical, and the arrows measured, stresses. 


\section{GREATEST STRESSES}

\section{THE LEGS}

From figures 29 to 32 , inclusive, it is evident that the ordinary theory for a beam subjected to combined axial and flexural loading predicts the stresses in the legs accurately. The agreement between the stresses computed from this theory and the measured stresses is close for the lower leg, and would probably have been equally close for the upper leg if there had been full bearing of the inner flanges of the legs at the inner corner of the knee.

\section{THE KNEE WEB}

The stresses in the knee web may exceed those in the legs. Expressions for the greatest stresses in the knee web are obtained below. By "greatest stress" will be understood the numerically largest stress.

\section{(a) GREATEST NORMAL STRESS}

The experimental results given in section IV indicate that the greatest normal stress in the knee web of frames of the type considered here occurs, as would be expected, at the inner corner, $x=a, y=b$. The greatest normal stress at this point may be obtained by evaluating eq 6,7 , and 8 for $\sigma_{x}, \sigma_{y}$, and $\tau_{x y}$ at $x=a, y=b$ and substituting the results in the expression

$$
\left.\begin{array}{l}
\sigma_{u} \\
\sigma_{v}
\end{array}\right\}=\frac{\sigma_{x}+\sigma_{y}}{2} \pm \sqrt{\left(\frac{\sigma_{x}-\sigma_{y}}{2}\right)^{2}+\tau_{x y}^{2}}
$$

If the applied load, as in figure 28 , tends to decrease the angle between the positive axes of $x$ and $y, \sigma_{v}$ will be numerically greater than $\sigma_{u}$ and a compressive stress. If the load is reversed (signs of $H$ and $V$ changed), $\sigma_{u}$ will be numerically greater than $\sigma_{v}$ and a tensile stress. In this case the discontinuous inner flange would transmit no stress to the knee, and the solution, approximate but on the safe side, would be obtained by taking $\lambda=\nu=0$.

Table 2 gives the greatest normal stresses in the rigid-frame specimen. The measured stresses are the stresses at a rosette. The computed stresses in the knee web were obtained from eq 16 (for $\sigma_{v}$ ) and those in the legs from eq 14.

TABLE 2.-Greatest normal stresses in the rigid-frame specimen

\begin{tabular}{|c|c|c|c|}
\hline \multirow{3}{*}{ Test } & \multicolumn{3}{|c|}{ Greatest normal stresses (compressive) } \\
\hline & \multicolumn{2}{|c|}{ Knee web } & \multirow{2}{*}{$\begin{array}{l}\text { Legs- } \\
\text { Computed }\end{array}$} \\
\hline & Measured & Computed & \\
\hline $\begin{array}{l}2 \\
4 \\
4 \\
5\end{array}$ & $\begin{array}{r}\text { kips/in.2 } \\
13.4 \\
14.5 \\
12.4 \\
13.1\end{array}$ & $\begin{array}{r}\text { kips/in.2 } \\
20.2 \\
17.5 \\
14.5 \\
15.2\end{array}$ & $\begin{array}{r}\text { kips/in.2 } \\
15.8 \\
13.4 \\
11.6 \\
13.9\end{array}$ \\
\hline
\end{tabular}


The computed greatest normal stresses in the knee web are somewhat higher than those in the legs.

\section{(b) GREATEST SHEARING STRESS}

The maximum shearing stress at any point in the knee web in terms of the normal stresses $\sigma_{x}$ and $\sigma_{y}$ and the shearing stress $\tau_{x \nu}$ is given by

$$
\tau_{\max }=\sqrt{\left(\frac{\sigma_{x}-\sigma_{y}}{2}\right)^{2}+\tau_{x y}^{2}} .
$$

To locate the point where $\tau_{\max }$ is a maximum, differentiate $\tau_{\max }^{2}$ partially with respect to $x$ and $y$ and set these derivatives equal to zero. One obtains

$$
\left.\begin{array}{rl}
\frac{\partial}{\partial x} \tau_{\text {max }}^{2}=\frac{1}{2}\left(\sigma_{x}-\sigma_{y}\right) \frac{\partial}{\partial x}\left(\sigma_{x}-\sigma_{y}\right)+2 \tau_{x y} \frac{\partial}{\partial x} \tau_{x y}=0 \\
\frac{\partial}{\partial y} \tau^{2}{ }_{\max }=\frac{1}{2}\left(\sigma_{x}-\sigma_{y}\right) \frac{\partial}{\partial y}\left(\sigma_{x}-\sigma_{y}\right)+2 \tau_{x y} \frac{\partial}{\partial y} \tau_{x y}=0 .
\end{array}\right\}
$$

Substitution of the values of $\sigma_{x}, \sigma_{y}$, and $\tau_{x y}$ from eq 2,3, and 4 into eq 18 gives, after some reduction,

$$
\left.\begin{array}{c}
{\left[\left(c_{3}+d_{4} y\right)(a+x)-\left(b_{3}+b_{4} x\right)(b+y)\right]\left[\left(c_{3}+d_{4} y\right)-b_{4}(b+y)\right]} \\
+4\left(b_{2}+b_{3} x+c_{3} y+\frac{1}{2} b_{4} x^{2}+\frac{1}{2} d_{4} y^{2}\right)\left(b_{3}+b_{4} x\right)=0, \\
{\left[\left(c_{3}+d_{4} y\right)(a+x)-\left(b_{3}+b_{4} x\right)(b+y)\right]\left[d_{4}(a+x)-\left(b_{3}+b_{4} x\right)\right]} \\
+4\left(b_{2}+b_{3} x+c_{3} y+\frac{1}{2} b_{4} x^{2}+\frac{1}{2} d_{4} y^{2}\right)\left(c_{3}+d_{4} y\right)=0 .
\end{array}\right\}
$$

A solution of eq 19 is seen by inspection to be

$$
x=-\frac{b_{3}}{b_{4}}, \quad y=-\frac{c_{3}}{d_{4}},
$$

and this is a possible location for the greatest maximum shearing stress, $\left(\tau_{\max }\right)_{\max }$. Evaluation of $x$ and $y$ by means of the relations 5 and 10 for the various cases of loading considered in this investigation and comparison with the measured stresses indicate that this is a significant and the only significant solution for the coordinates of the point where $\tau_{\max }$ is a maximum. The values of $x$ and $y$ given by eq 20 make $\sigma_{x}=\sigma_{y}=0$ (eq 2 and 3 ) and therefore (eq 17)

$$
\left(\tau_{\max }\right)_{\max }=\left(\tau_{x y}\right)_{\max } .
$$

The maximum shearing stress may then be obtained simply from eq 4 by inserting the values just found for $x$ and $y$. 
Table 3 gives the greatest shearing stresses in the rigid-frame specimen. The measured stresses are the stresses at a rosette. The computed stresses in the knee web were obtained as just explained, and those in the leg webs from eq 15 . The shearing stresses in the knee web are much larger than those in the leg webs.

TABLE 3.-Greatest shearing stresses in the rigid-frame specimen

\begin{tabular}{|c|c|c|c|}
\hline \multirow{3}{*}{ Test } & \multicolumn{3}{|c|}{ Greatest shearing stresses } \\
\hline & \multicolumn{2}{|c|}{ Knee web } & \multirow{2}{*}{$\begin{array}{l}\text { Leg webs- } \\
\text { Computed }\end{array}$} \\
\hline & Measured & Computed & \\
\hline 5 & $\begin{array}{r}\text { kips/in.2 } \\
10.2 \\
8.8 \\
6.7 \\
8.7\end{array}$ & $\begin{array}{r}\text { kips/in.2 } \\
11.8 \\
9.6 \\
7.8 \\
8.8\end{array}$ & $\begin{array}{r}\text { kips/in. } \\
\text { 4. } \\
4.6 \\
4.6 \\
4.8 \\
5.2\end{array}$ \\
\hline
\end{tabular}

\section{MAXIMUM LOAD}

The rigid-frame specimen is shown in figure 33 in the testing machine for determining the maximum load. The load line was the same as for test 2, and the gussets had been removed from the outer corner. The steel structure shown in figure 33 prevented lateral deflection of the outer corner of the specimen. Before loading, the specimen was coated with a cement wash to make Lüders' lines clearly visible where the material was stressed to the yield point during the test.

The maximum load sustained by the specimen was $168,000 \mathrm{lb}$. Failure occurred by lateral deflection of the inner corner with attendant buckling of the outstanding legs of the inner flange angles on one side, as shown in figure 34 . No rivets failed, so far as could be noticed visually. For test 2, the ratio of the load to the greatest measured stress was 4.35 kips per kip/in ${ }^{2}$. The ratio of the maximum load to the tensile yield point of the angles (see table 1) was 4.31 kips per kip/in ${ }^{2}$. If one assumes a linear variation of stress with load up to the yield point and the compressive and tensile yield points to be equal, it is evident that practically the full compressive strength of the material was utilized.

The knee web after failure is shown in figure 35 . The Lüders' lines, which run horizontally and vertically, are clearly visible. The diagonal streak of granulated appearance parallel to the load line is due to a buckle in the web.

\section{CONCLUSIONS}

The distribution of stress in a riveted steel rigid-frame specimen having straight flanges was determined experimentally and theoretically, and the maximum load was measured. The following conclusions were drawn:

1. The stresses at the outer corner of the knee of the specimen were small, and reinforcing the outer corner had a negligible effect on the distribution of stress in the specimen. 


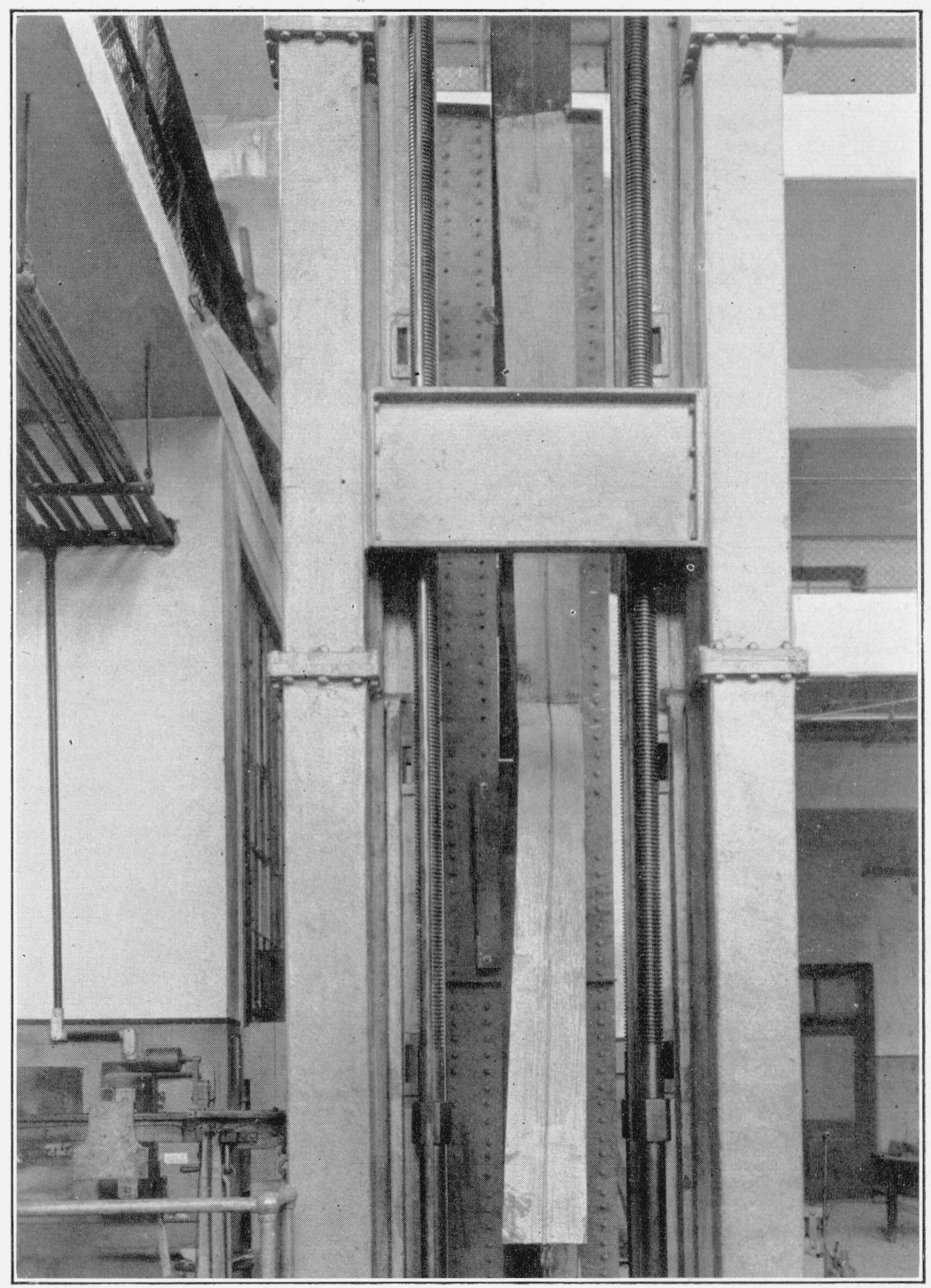

FIGURE 33.-Rigid-frame specimen ai the maximum load of 168,000 $\mathrm{lb}$. 


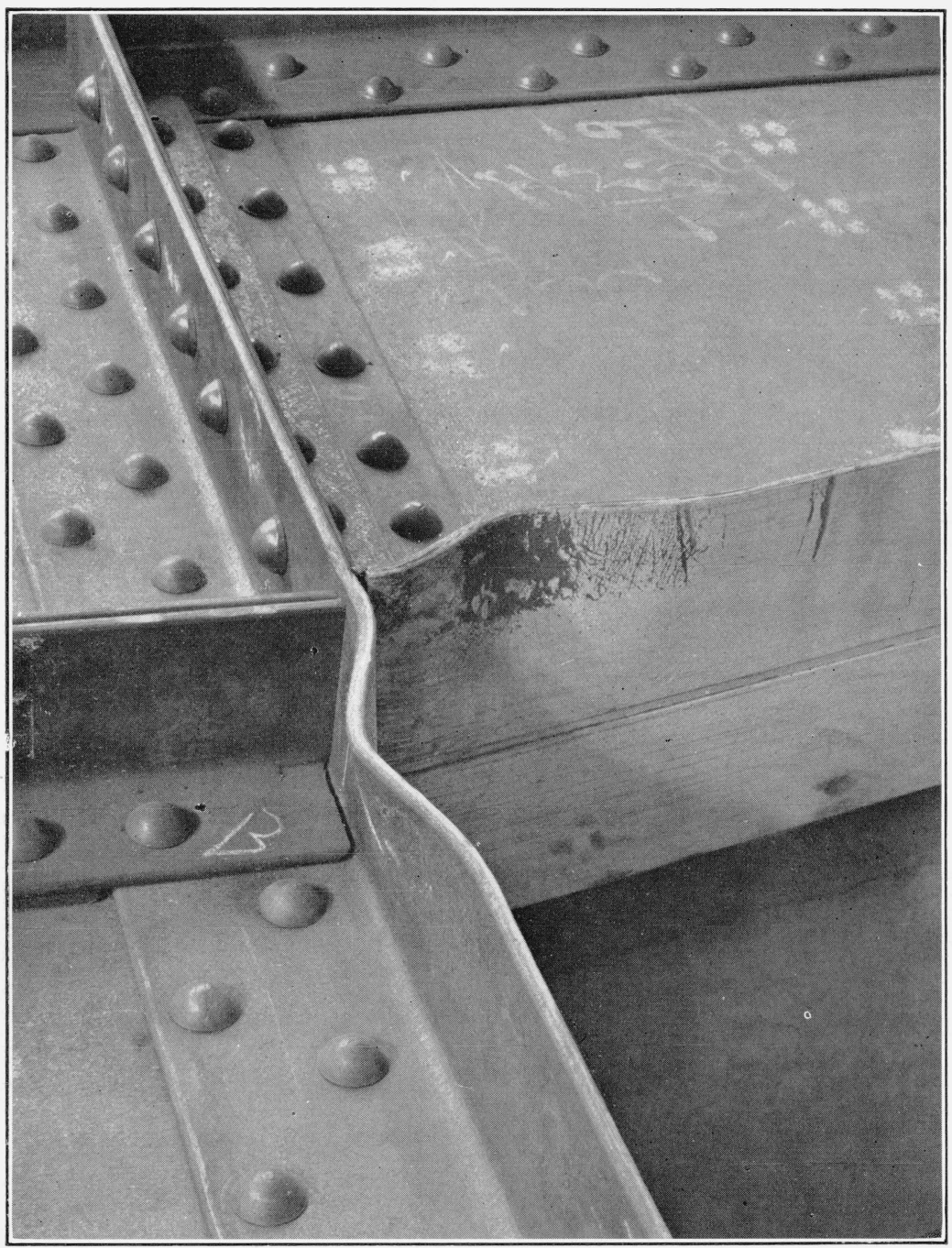

FIGURE 34.-Inner corner of the knee of the rigid-frame specimen after failure. 


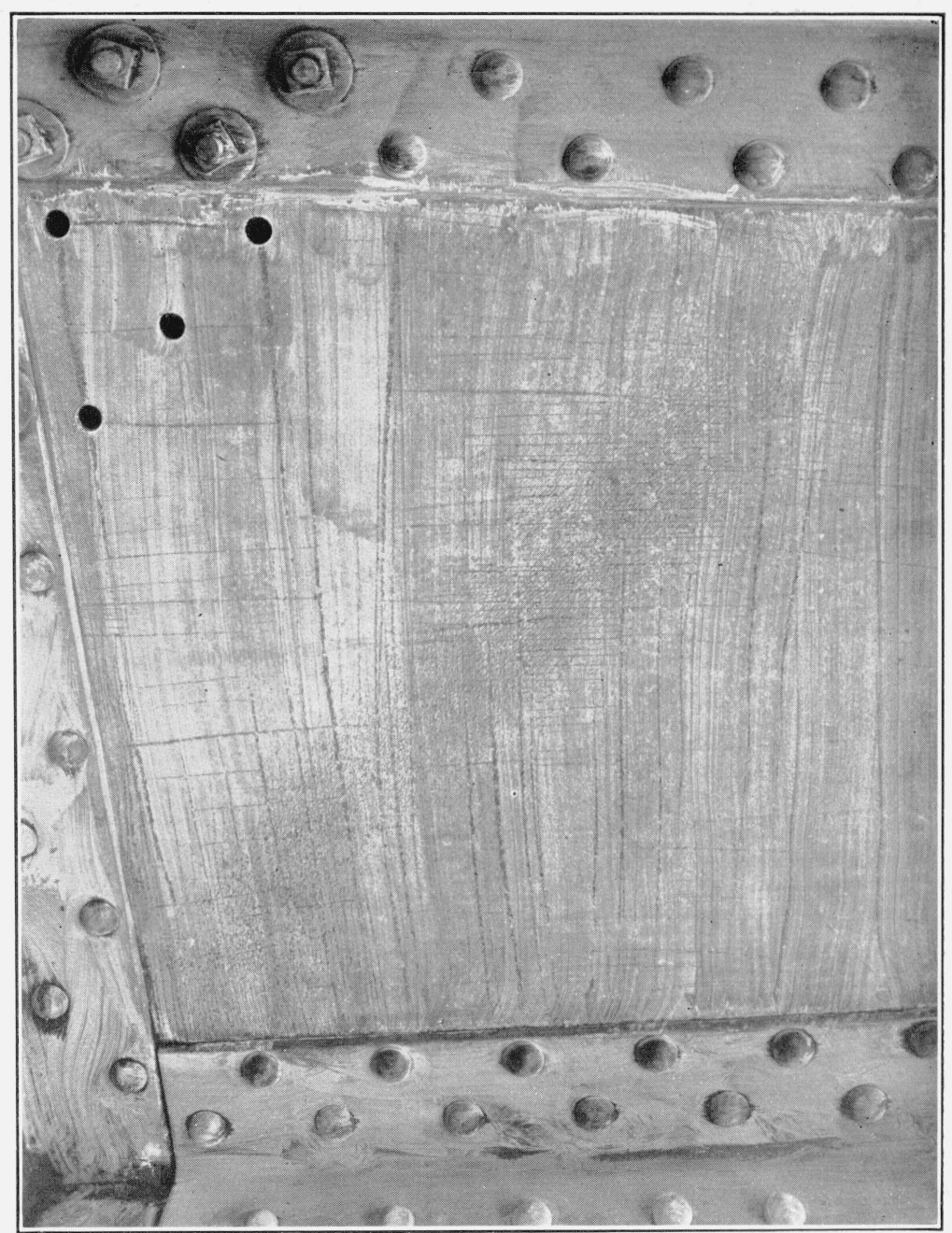

FIGURE 35.-Knee web of the rigid-frame specimen after failure. 
2. The ordinary beam theory gives stresses in the legs in satisfactory agreement with those obtained experimentally.

3 . The formulas developed for the computation of the stresses in the knee give stresses in satisfactory agreement with those obtained experimentally.

4. The material of the frame was so disposed as to develop its full yield strength in compression.

5. Bearing of the discontinuous inner flange against the continuous one, and of the latter against the stiffeners, is essential to prevent possibility of overstressing the webs.

\section{APPENDIX - STRESSES FROM STRAIN DATA}

In the case of plane stress three quantities are required to determine completely the state of stress at a point. These may be taken as two normal stresses and a shearing stress with respect to a given set of axes, or as the two principal stresses and the direction of one of them with respect to a given set of axes. In order to determine the state of stress from measurements of strain, in addition to the elastic constants of the material, ${ }^{5}$ the strains at a point in at least three directions must be known. If the strains are known in more than three directions, the data are redundant, and the solution for the stresses may be obtained by the method of least squares or in some other way.

A graphical solution for the stresses from strains on three intersecting gage lines has been given by Osgood and Sturm [12]. The analy tical solutions are summarized below.

Let $\epsilon$ denote strain and the subscript to $\epsilon$ the gage line along which the strain is measured. Gage lines 1 and 3 in figure 36 are at right angles to each other. Gage lines 2 and 4 are at right angles to each other and at $45^{\circ}$ to gage lines 1 and 3 . Gage lines $a, b$, and $c$ in figure 37 are mutually at $120^{\circ}$. Then, if $E$ is Young's modulus of elasticity, the following formulas give the maximum principal stress, $\sigma_{u}$; the minimum principal stress, $\sigma_{v}$; and the angle $\theta$, measured

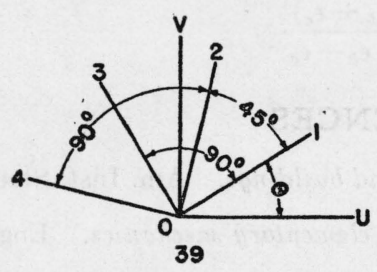

FIGURE 36.-Four gage lines (1, 2, 3, 4) intersecting at $0 . \quad D i$ rections $(u, v)$ of principal stresses.

As shown above, the angle $\theta$ is positive.

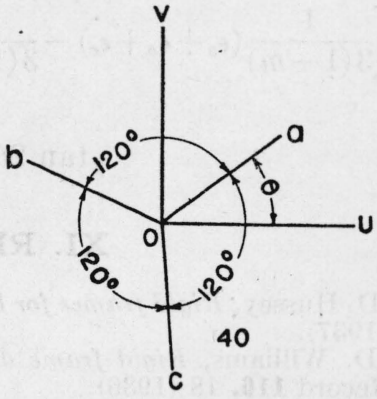

FIGURE 37.-Three gagelines (a, $b, c)$ intersecting at 0 . Directions $(u, v)$ of principal stresses.

As shown above, the angle $\theta$ is positive.

'Young's modulus of elasticity and Poisson's ratio. A homogeneous isotropic material is assumed. 
positive in the 123 or $a b c$ direction from the direction of $\sigma_{u}$ to gage line 1, or gage line $a$.

Case 1.-Strains measured on gage lines 1, 2, 3, 4 [13, 14]. Poisson's ratio taken as $1 / 3$.

$$
\begin{gathered}
\sigma_{u}=\frac{3}{8} E\left[\epsilon_{1}+\epsilon_{2}+\epsilon_{3}+\epsilon_{4}+\sqrt{\left(\epsilon_{1}-\epsilon_{3}\right)^{2}+\left(\epsilon_{2}-\epsilon_{4}\right)^{2}}\right] \\
\sigma_{v}=\frac{3}{8} E\left[\epsilon_{1}+\epsilon_{2}+\epsilon_{3}+\epsilon_{4}-\sqrt{\left(\epsilon_{1}-\epsilon_{3}\right)^{2}+\left(\epsilon_{2}-\epsilon_{4}\right)^{2}}\right], \\
\tan 2 \theta=-\frac{\epsilon_{2}-\epsilon_{4}}{\epsilon_{1}-\epsilon_{3}} .
\end{gathered}
$$

When the solution of these equations is required a large number of times, the work may be facilitated by the use of nomographic charts [15].

Case 2.-Strains measured on gage lines 1, 2, $3\left(\epsilon_{4}=\epsilon_{1}+\epsilon_{3}-\epsilon_{2}\right.$ in case 1). Poisson's ratio taken as 1/3.

$$
\begin{gathered}
\sigma_{u}=\frac{3}{8} E\left[2\left(\epsilon_{1}+\epsilon_{3}\right)+\sqrt{\left(\epsilon_{1}-\epsilon_{3}\right)^{2}+\left(\epsilon_{1}-2 \epsilon_{2}+\epsilon_{3}\right)^{2}}\right], \\
\sigma_{v}=\frac{3}{8} E\left[2\left(\epsilon_{1}+\epsilon_{3}\right)-\sqrt{\left(\epsilon_{1}-\epsilon_{3}\right)^{2}+\left(\epsilon_{1}-2 \epsilon_{2}+\epsilon_{3}\right)^{2}}\right], \\
\tan 2 \theta=\frac{\epsilon_{1}-2 \epsilon_{2}+\epsilon_{3}}{\epsilon_{1}-\epsilon_{3}} .
\end{gathered}
$$

Case 3.-Strains measured on gage lines $a, b, c[16] . \quad m=$ Poisson's ratio.

$$
\begin{gathered}
\sigma_{u}=E\left[\frac{1}{3(1-m)}\left(\epsilon_{a}+\epsilon_{b}+\epsilon_{c}\right)+\frac{\sqrt{2}}{3(1+m)} \sqrt{\left(\epsilon_{a}-\epsilon_{b}\right)^{2}+\left(\epsilon_{b}-\epsilon_{c}\right)^{2}+\left(\epsilon_{c}-\epsilon_{a}\right)^{2}}\right] \\
\sigma_{v}=E\left[\frac{1}{3(1-m)}\left(\epsilon_{a}+\epsilon_{b}+\epsilon_{c}\right)-\frac{\sqrt{2}}{3(1+m)} \sqrt{\left(\epsilon_{a}-\epsilon_{b}\right)^{2}+\left(\epsilon_{b}-\epsilon_{c}\right)^{2}+\left(\epsilon_{c}-\epsilon_{a}\right)^{2}}\right], \\
\tan 2 \theta=\frac{\sqrt{3}\left(\epsilon_{b}-\epsilon_{c}\right)}{2 \epsilon_{a}-\epsilon_{b}-\epsilon_{c}} .
\end{gathered}
$$

\section{REFERENCES}

[1] H. D. Hussey, Rigid frames for bridges and buildings. Am. Inst. Steel Const. (1937).

[2] C. D. Williams, Rigid frame design by elementary mechanics. Eng. NewsRecord 116, 18 (1936).

[3] J. M. Frankland, The analysis of multiple-span rigid frame bridges by Castigliano's Theorem. Am. Inst. Steel Const. (1934).

[4] H. C. von Widdern, Polarisationsoptische Spannungsmessungen an Stabecken. Mitteilungen aus dem Mechanisch-Technischen Laboratorium der Technischen Hochschule München, No. 34, Theodor Ackermann, Munich.

[5] H. Kurzhals, Polarisationsoptische Untersuchungen an rechtwinkeligen auf Biegung beanspruchten Stabecken. Theodor Ackermann, Munich.

[6] F. E. Richart and T. A. Olson, Rapid and long time tests on reinforced concrete knee frames. J. Am. Concrete Inst. 8, 474 (1937). 
[7] Standard specifications for steel for bridges. Fig. 1, ASTM Standards pt. I, 4 (1936).

[8] L. B. Tuckerman, Discussion on proportional limit. Proc. Am. Soc. Testing Materials 29, pt. II, 538 (1929).

[9] G. Grüning, Spannungsverteilung in stählernen Rahmenecken. Der Bauingenieur 18, 158 (1937).

[10] S. Timoshenko, Theory of elasticity, Chap. 2. (McGraw-Hill Book Co., Inc., New York, N. Y., 1934.)

[11] Specification for the design, fabrication, and erection of structural steel for buildings. Steel Construction (Am. Inst. Steel Const. 259, New York, N. Y. 1937).

[12] Wm. R. Osgood and Rolland G. Sturm, The determination of stresses from strains on three intersecting gage lines and its application to actual tests. J. Research NBS 10, 685 (1933) RP559.

[13] Wm. R. Osgood, Determination of principal stresses from strains on four intersecting gage lines $45^{\circ}$ apart. J. Research NBS 15, 579 (1935) RP851.

[14] Georg Schnadel, Die Spannungsverteilung in den Flanschen dünnwandiger Kastenträger. Jahrb. Schiffbautechnischen Ges. 27, 246 (1926).

[15] Ambrose H. Stang and Martin Greenspan, Graphical computation of stresses from strain data. J. Research NBS 19, 437 (1937) RP1034.

[16] O. S. Heck, Untersuchung ebener Spannungszustände mit Hilfe von Dehnungsmessern. Ing.-Arch. 8, 30 (1937).

Washington, June 7, 1938. 